\title{
A systematic review and meta-analysis of the relationship between flow states and performance
}

\author{
David J. Harris, Kate L. Allen, Samuel J. Vine \& Mark R. Wilson
}

To cite this article: David J. Harris, Kate L. Allen, Samuel J. Vine \& Mark R. Wilson (2021): A systematic review and meta-analysis of the relationship between flow states and performance, International Review of Sport and Exercise Psychology, DOI: 10.1080/1750984X.2021.1929402

To link to this article: https://doi.org/10.1080/1750984X.2021.1929402

○ (c) 2021 The Author(s). Published by Informa UK Limited, trading as Taylor \& Francis Group

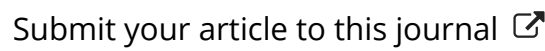

Q View related articles ¿

Citing articles: 1 View citing articles $ک \pi$
Published online: 27 May 2021.

III Article views: 1613

View Crossmark data $\widetilde{ }$ 


\title{
A systematic review and meta-analysis of the relationship between flow states and performance
}

\author{
David J. Harris $\mathbb{B D}^{\mathrm{a}}$, Kate L. Allen $\mathbb{( D}^{\mathrm{b}}$, Samuel J. Vine $\mathbb{( D}^{\mathrm{a}}$ and Mark R. Wilson (D) ${ }^{\mathrm{a}}$ \\ ${ }^{a}$ School of Sport and Health Sciences, University of Exeter, Exeter, UK; ${ }^{b}$ Medical School, Children and Young \\ People's Mental Health Collaboration (ChYMe), Institute of Health Research, University of Exeter, Exeter, UK
}

\begin{abstract}
Flow is an optimal experience that has received particular interest within sport because of a possible relationship with enhanced athletic performances. Yet, the strength and direction of the putative flow-performance relationship remain unclear. Consequently, a PRISMA guided systematic review was conducted in May 2020 to examine the empirical evidence for a flowperformance relationship, to examine potential mechanisms, and to assess the quality of current evidence. Peer-reviewed articles that examined the relationship between flow and performance in sport or computer gaming tasks were searched for using five online databases. The results were collated into a narrative synthesis and a meta-analysis. Twenty articles met the inclusion criteria, featuring 22 studies that were appropriate for metaanalysis. The overall quality of the studies was fairly good, with a mean quality assessment score of $76.5 \%(S D=9.7)$. The pooled effect size $(r=0.31,95 \% \mathrm{Cl}[0.24 ; 0.38])$ indicated that across a range of sport and gaming tasks there was a medium-sized flowperformance relationship. However, current evidence is unable to determine the causal direction of this relationship or the mechanisms that mediate it. A number of conceptual and methodological challenges facing the study of flow are discussed and recommendations for future work are outlined.
\end{abstract}

ARTICLE HISTORY

Received 25 October 2020

Accepted 7 May 2021

\section{KEYWORDS}

Sport; the zone; peak performance; optimal experience; gaming

\section{Introduction}

Engaging in recreational activities such as sport or computer gaming has the potential to be highly rewarding, enjoyable and motivating (Beedie et al., 2000; Robazza, 2006). One of the most positive and rewarding mental states that can be achieved during these activities is flow (Jackson \& Csikszentmihalyi, 1999). Flow is an experience of total absorption in the present activity, which can lead to performances feeling effortless and enjoyable (Csikszentmihalyi \& Lefevre, 1989). Research into flow originated from the early work of Mihaly Csikszentmihalyi, who wished to understand how and why people could become so committed to particular activities that provided no obvious external rewards (Csikszentmihalyi, 1975). Falling within the tradition of positive psychology, 
much work on flow has focused on how it can enrich people's lives (Csikszentmihalyi, 2000). Yet interest in flow is often derived from a rather more pragmatic concern with its performance-enhancing effects.

In the sport literature, flow is routinely described as underlying peak or enhanced performances (Jackson et al., 2001; Jackson \& Csikszentmihalyi, 1999; Norsworthy et al., 2017; Swann et al., 2017). Given that flow is associated with functional characteristics like feeling focused, motivated and confident, the link to performance is appealing (Landhäußer \& Keller, 2012). Indeed, Swann and colleagues (Swann et al., 2016, 2017) have described flow as one of two possible routes for achieving enhanced athletic performances (the other more deliberate route is described as 'clutch' or 'making it happen'). A correlation between flow and performance has also been noted in the computer gaming literature (Engeser \& Rheinberg, 2008; Keller \& Blomann, 2008). Computer games are highly engaging and conducive to flow and overlap with a number of elements of sport (e.g. demands on perceptual, attentional, and motor abilities), as evidenced by recent research into the psychology of so-called Esports (Campbell et al., 2018; Pedraza-Ramirez et al., 2020). That a flow-performance relationship also exists in this domain suggests that there may be generally beneficial effects that extend beyond (physical) sport. However, the intuitive lure of a flow-performance relationship means it has largely escaped critical appraisal; both the strength and the causal direction of the flow-performance relationship remain unclear (Moran \& Toner, 2017; Swann et al., 2018). Hence, before flow can become a foundation for interventions in sport (Aherne et al., 2011; Nicholls et al., 2005), or a component of theoretical accounts of excellent performance (Swann et al., 2017), a more rigorous evaluation of the flow-performance relationship is needed.

Csikszentmihalyi's original conceptualisation of flow outlines nine critical dimensions; three describing the proximal or preconditions for the experience, and six describing the phenomenology (Kawabata \& Mallett, 2011; Nakamura \& Csikszentmihalyi, 2002). The proximal conditions are: (i) a challenge-skill balance (i.e. an evaluation that the demands of the activity match with one's ability); (ii) clear goals; and (iii) unambiguous feedback about the effect of one's actions. Sport is particularly well-suited to provide these preconditions, although their presence does not necessitate the occurrence of flow. The experiential components of flow are: (i) merging of action and awareness; (ii) concentration on the task at hand; (iii) a sense of control; (iv) a loss of self-consciousness; (v) transformation of time; and (vi) autotelic experience (i.e. the activity is intrinsically rewarding). An alternative conceptualisation by Stavrou and Zervas (2004) has described challenge-skill balance, clear goals, unambiguous feedback, concentration on the task, and sense of control as antecedents, while action-awareness merging, loss of self-consciousness, transformation of time, and autotelic experience are described as consequences of flow. These four factors might be the most relevant for the flowperformance relationship given their temporal relationship with the experience (i.e. occurring during, rather than before the experience).

In sport much research has focused on the relationship of flow with performance (Jackson et al., 2001; Swann et al., 2017), antecedents of flow (Koehn et al., 2018; Swann et al., 2012) and interventions to increase flow (Aherne et al., 2011). The core components of the flow experience do appear to be functional for task performance (Fong et al., 2015; Landhäußer \& Keller, 2012) in the context of sport, or aligned tasks like Esports or computer gaming. These include intrinsic motivation, high levels of 
concentration, and focusing on the goal not the self, all of which are likely to provide performance benefits (Hagger \& Chatzisarantis, 2007; Roberts et al., 2019; Yarrow et al., 2009). Additionally, the experience of anxiety - with its negative consequences for skill execution (Eysenck \& Wilson, 2016; Nieuwenhuys \& Oudejans, 2012) - seems to be absent from flow. ${ }^{1}$

Clear mechanistic accounts of how flow may enhance performance are, however, lacking. In a prominent model of the flow experience, the Transient Hypofrontality Hypothesis, Arne Dietrich (2003) suggested that flow arises from a widespread inhibition of activation within the prefrontal cortex (PFC). The resulting reduction in higher cognitive processing (e.g. abstract thinking, self-reflection) is proposed to be responsible for the phenomenology of flow, as well as facilitating expert-like execution of well-learned skills through avoidance of disruptive conscious control (Dietrich, 2003). While an increased automaticity of action would have unmistakable benefits for performance, a general reduction in abstract thought during flow in sport is likely to be an oversimplification ${ }^{2}$ (Harris et al., 2017a; Yoshida et al., 2014). Consequently, more complete explanations are required.

In addition to the possible transitory benefits provided by flow, enhanced performances across a longer timescale may also occur. Intrinsic motivation, which accompanies flow, is known to support long-term perseverance and engagement in recreational activities, which is likely to result in skill development (Cseh et al., 2015). This effect can be conceptualised as a growth principle, with the rewarding experience of flow leading to increasingly more complex demands being sought. Consequently, Landhäußer and Keller (2012) have previously characterised flow as having dual performance-enhancing effects: a direct effect on performance due to the functional mental state, plus an indirect effect via motivation and engagement.

Despite a number of reasons to expect flow to be performance enhancing, there has been no systematic review and critical appraisal of this relationship. The apparent benefits of flow for sport performance (motivation, focused attention, avoidance of self-focus) imply that achieving flow would lead to better outcomes. Yet in the literature, flow and performance are often referred to using vague terms like 'linked with' or 'associated with' which betray researchers' uncertainty about the direction of this relationship (Jackson et al., 2001; Swann et al., 2017). Additionally, initial good performance may also initiate a flow experience (Swann et al., 2017), suggesting that an effect in the opposite direction (or a reciprocal effect) might be possible.

As a result of the myriad of benefits that flow might provide, few clear mechanistic accounts of performance enhancement have been outlined (although a partial one is provided by Dietrich, 2003). One promising mechanism for a flow-performance relationship is the improvement in attention that is associated with flow. Efficient control of attention is a major factor in sports (Mann et al., 2007; Yarrow et al., 2009) and Esports (Campbell et al., 2018) expertise, and could account for performance enhancements in flow (Harris et al., 2017b; Marty-Dugas \& Smilek, 2019). Therefore, we aimed to investigate not only whether a flow-performance relationship exists but whether existing studies have either proposed or assessed potential mechanisms, such as attention.

As systematic reviews serve to highlight research gaps and suggest directions for future empirical work (Gurevitch et al., 2018; Petticrew \& Roberts, 2008) a review of the flow-performance relationship could be highly valuable for a theoretical understanding of flow, as well as for designing effective interventions. In reviewing the current state 
of flow research, Swann et al. (2018) discussed how work to date has tended to avoid questions about causality, which has held-back our theoretical understanding, as well as limiting the effectiveness of practical applications. Accordingly, clearer, testable predictions about causal directions as well as intervening mechanisms need to be outlined. Consequently, the present review aims to identify what evidence currently exists for a causal relationship between flow and performance (and the direction it takes) and to clearly outline the intervening mechanisms proposed in the literature. Our wider objective is to provide a more detailed assessment of flow and performance to support future work in moving towards clearer predictions and testing of this relationship. Previous systematic reviews into flow states have examined the challenge-skill balance and antecedents of flow (Fong et al., 2015), flow in exercise (Jackman et al., 2019), the experience, occurrence, and perceived controllability of flow in elite sport (Swann et al., 2012), and flow in adventure recreation (Boudreau et al., 2020). But the performance benefits of flow have not been systematically evaluated. Therefore, this review aimed to synthesise existing research on flow and performance.

In order to provide a review that was maximally informative for sport but also for a wider understanding of flow, the review included research from both sport and computer gaming tasks. There has been considerable work on flow in computer gaming, which has similarly identified links between flow and performance (Engeser \& Rheinberg, 2008). Gaming was deemed to be highly relevant for understanding how flow might improve sport performance because there is substantial overlap between sport and gaming skills, in terms of perceptual, attentional, motor and decision-making abilities that underpin performance in both (Jenny et al., 2017; van Hilvoorde \& Pot, 2016). Indeed, both sport and gaming could be described as highly skilled visuomotor tasks, requiring the integration of visual input with motor output. The two tasks differ in important ways such as the degree of physical exertion and the psychological effects related to physical effort - but given the overlapping elements, findings from gaming were deemed important for understanding the flow-performance relationship in sport (Campbell et al., 2018; Pedraza-Ramirez et al., 2020). Indeed, with the growth of E-sports the line between the two is becoming increasingly blurred (Holt, 2016; Jenny et al., 2017). Additionally, both sport and gaming provide objective measures of performance that enable the relationship with flow to be quantified. Therefore, the review addressed research using sport, gaming and simulated sport tasks. In reviewing this literature, we sought to address the following research questions:

(i) Is there reliable evidence for a relationship between flow and performance?

(ii) What is the nature of this relationship (i.e. direction of causality)?

(iii) What is the quality of the research in this field?

(iv) What evidence is there regarding mechanisms that link flow to performance?

\section{Method}

\section{Protocol}

The review procedures followed the Preferred Reporting Items for Systematic Reviews and Meta-analyses (PRISMA) Statement (Moher et al., 2009). The PRISMA checklist is 
available as a supplementary file. The systematic review, search strategy and meta-analysis were detailed in a preregistration document, which is available from the Open Science Framework, as are all supplementary files (https://osf.io/3hfcu/).

\section{Search strategy}

The literature search was conducted using five online databases: PsycARTICLES; PsycINFO; MEDLINE; SPORTSDiscus; and the Psychology and Behavioural Science Collection. The databases were searched from inception to 13th May 2020, the date the final search was conducted. The search string contained the following Boolean search terms: [flow AND (state* OR experienc* OR theory)] AND (perform* OR skill* OR accura*) NOT (expirat* flow OR optic* flow OR water flow OR gene* flow). These keywords were based on previous systematic reviews in related areas (Jackman et al., 2019; Swann et al., 2012), initial scoping searches by the first author and discussions between all authors following the initial searches. We searched for flow in combination with perform* OR skill* OR accura* to identify papers that had measured some kind of skill execution, accuracy, or performance element in addition to flow state. The search string was slightly adapted for each database (see supplementary materials for a breakdown of individual database terms) to maximise search effectiveness. Truncated terms (e.g. perform ${ }^{*}$ ) were used to capture as many spelling variants as possible. Next, further searches for relevant titles and abstracts were performed by the first author to identify additional papers not returned in the initial searches. This was achieved through forward and backward citation chasing. Reference lists of included studies were searched for potentially relevant titles and forward citations of the identified studies were searched through Google Scholar. All returned results were exported into Endnote X9 reference management software and duplicate items were removed using a combination of automatic and manual de-duplication.

\section{Eligibility criteria}

A set of inclusion and exclusion criteria were established to guide the selection of papers for the review and ensure that all literature relevant to the review objectives was found. The eligibility criteria reflected the aim of quantifying the strength of the flow-performance relationship in sport and related tasks with clear performance outcomes (i.e. also computer gaming and sport simulations). Self-reports of performance were not considered appropriate as the outcome can easily bias retrospective introspection (Brewer et al., 1991) and self-report suffers from common methods variance issues that are likely to inflate effect sizes (Podsakoff et al., 2003). Consequently, tasks such as music or exergames that did not have clear performance measures were not included. Therefore, the literature included in this review met the following criteria: (i) was published in peer-reviewed journals; (ii) was published in English (the first language of the authors); (iii) contained original empirical data; (iv) used a quantitative (and not selfreport) measurement of task performance; ( $v$ ) measured flow in a sport, ${ }^{3}$ simulated sport or a computer gaming task; and (vi) quantitatively assessed the relationship between flow and performance. 
The exclusion criteria specified that studies were ineligible when they: (i) did not use a quantitative performance measurement; (ii) used tasks other than sport, simulated sport or computer gaming; (iii) were written in a language other than English; (iv) were review papers, commentaries or scale validation studies; ( $v$ ) or used a single-subject design. Review papers, scale validation studies and single-subject designs were excluded because they did not allow a quantitative analysis of the flow-performance relationship.

\section{Screening process}

All titles and abstracts retrieved from the searches were initially read and checked for eligibility against the eligibility checklist described above. This process was performed independently by both the first and second authors. Initially there was $85.1 \%$ agreement (Cohen's $k=0.41$ ) for inclusion/exclusion selections. The remaining discrepancies in inclusion/exclusion were then re-reviewed and resolved by discussion. Next, full texts were obtained for all articles included during the screening stage. These full texts were read by both the first and second authors to check for eligibility in relation to the criteria. Any studies not meeting the criteria were excluded (see PRISMA flow diagram in supplementary materials) and any disagreements were resolved through discussion.

\section{Data extraction, analysis, and synthesis}

Data extraction from the final selection of studies was performed by the first author. All studies were read twice to enhance familiarity with the data before extracting and synthesising the findings (Cuijpers, 2016; Petticrew \& Roberts, 2008). Based on recommendations in Popay et al. (2006), the following data fields were extracted: authors; date of publication; participant sample characteristics; flow activity; performance measure; design; flow measurement method; key findings; and proposed mechanism (i.e. was a mechanism for any performance effect proposed or measured).

\section{Assessment of study quality}

Assessment of study quality aids interpretation of findings by providing an index of the reliability of the evidence and whether studies reached an acceptable scientific standard (Borenstein et al., 2009; Petticrew \& Roberts, 2008). As in Payne et al. (2019) and Harris et al. (2018) a quality assessment scale was adapted from the Quality Index (Downs \& Black, 1998), the Checklist for the Evaluation of Research Articles (Durant, 1994) and the Appraisal Instrument (Genaidy et al., 2007). Quality assessment was primarily conducted by the first author. The quality assessment items and individual scores are available in the supplementary materials (see: https://osf.io/3hfcu/).

\section{Quantitative synthesis}

Borenstein et al. (2009) outline that the suitability of quantitative synthesis for studies employing varying measures depends on whether the research question aims to (i) provide a more reliable estimate of a very narrow effect, or (ii) examine the diversity of findings in relation to a broader effect. As the aim of the current investigation is very much the latter - we aimed to examine the flow-performance relationship across a range of tasks, settings and populations - a quantitative synthesis was chosen (Gurevitch 
et al., 2018). However, when interpreting these results, it is important to acknowledge the heterogeneity of measurement instruments (i.e. flow scales) and tasks.

To calculate a pooled effect size from all studies included in the systematic review, the effect size for the flow-performance relationship was extracted from each study. ${ }^{4}$ The effect size from each study was weighted in the analysis according to their sample size (n). As most studies reported correlational analyses, the meta-analysis was run using $r$ values. Two studies (Jin, 2012; Schmidt et al., 2020) compared differences in flow scores between successful and unsuccessful outcomes, so Cohen's $d$ was converted to $r$ using the following formula outlined in Borenstein et al. (2009):

$$
r=\frac{d}{\sqrt{d^{2}+a}}
$$

where $a$ is a correction factor for cases where $n 1 n 2$,

$$
a=\frac{\left(n_{1}+n_{2}\right)^{2}}{n_{1} n_{2}}
$$

A pooled effect size was calculated using the 'metafor' package for $\mathrm{R}$ (Viechtbauer, 2010). As the effect sizes used in the quantitative synthesis did not stem from a homogenous population, a random-effects model was chosen to better account for statistical heterogeneity and dependencies within studies (Borenstein et al., 2009). The randomeffects model assumes that, as the studies draw from varying populations, there is not only one true effect size, but a distribution of true effect sizes, from which we aim to estimate the mean (Cuijpers, 2016; Harrer et al., 2019). Variance of the distribution of true effect sizes, which is denoted by $\tau^{2}$ and $I^{2}$, was calculated using the Hartung-KnappSidik-Jonkman (HKSJ) method (IntHout et al., 2014). Sub-group analyses were also performed for task (sport or gaming). As discussed, sport and gaming tasks share overlapping cognitive and motor elements so it was decided that a combined analysis was appropriate, but that subgroup analyses to compare the two clusters of studies would also be informative.

In smaller meta-analyses, it is possible for individual studies to have a disproportionate effect on the overall pooled effect size estimate. In order to understand whether this was the case here, we first performed a 'leave-one-out' analysis. This approach re-calculates the pooled effect $k$ times leaving out one study for each analysis to determine whether the omission of any single study heavily biases the overall effect. Additionally, we performed a combinatorial meta-analysis to explore whether any group of studies had a biasing effect on the overall estimate (Olkin et al., 2012). The combinatorial analysis runs meta-analyses on all possible combinations of the included studies (i.e. $2 \wedge k-1$ ).

\section{Narrative synthesis}

Key findings and themes from the included studies were identified using an interpretative and integrative narrative synthesis (Popay et al., 2006). This approach aims to develop a preliminary synthesis of the findings, then explore themes and relationships in the findings and relate them back to the research questions. To achieve this, the included studies were read at least twice, and key findings were summarised in tables (Table 1) to provide an overview of the research. In line with the key research questions of the 


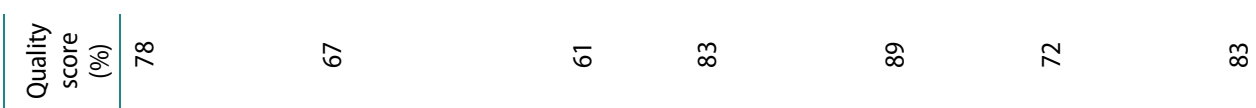

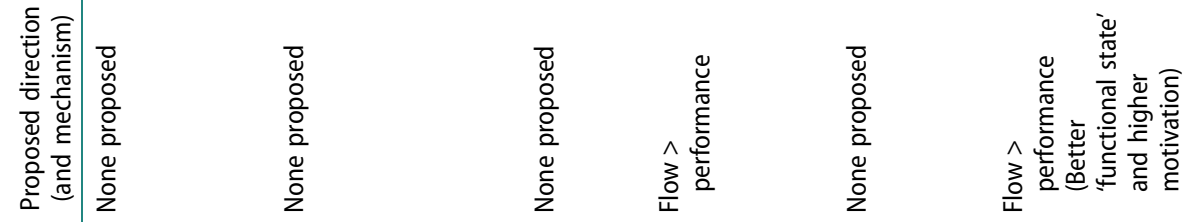

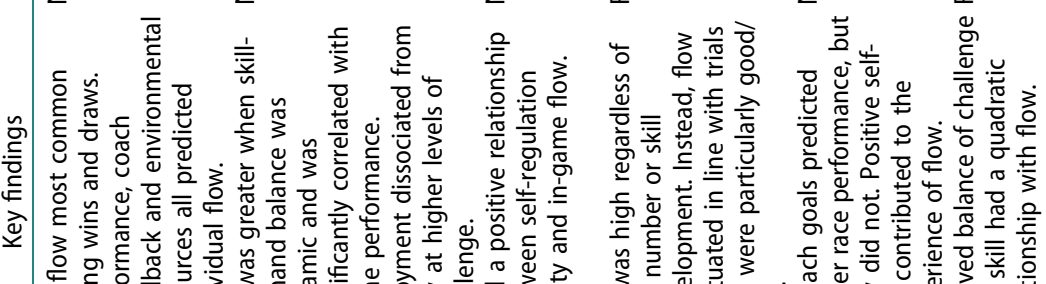

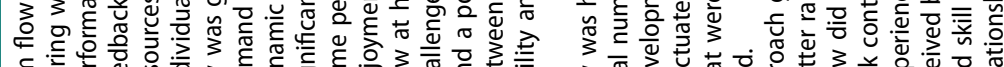

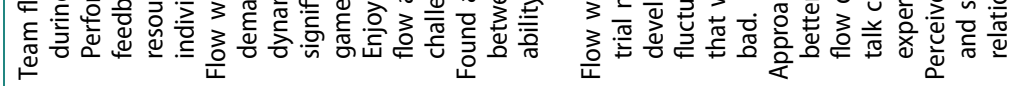
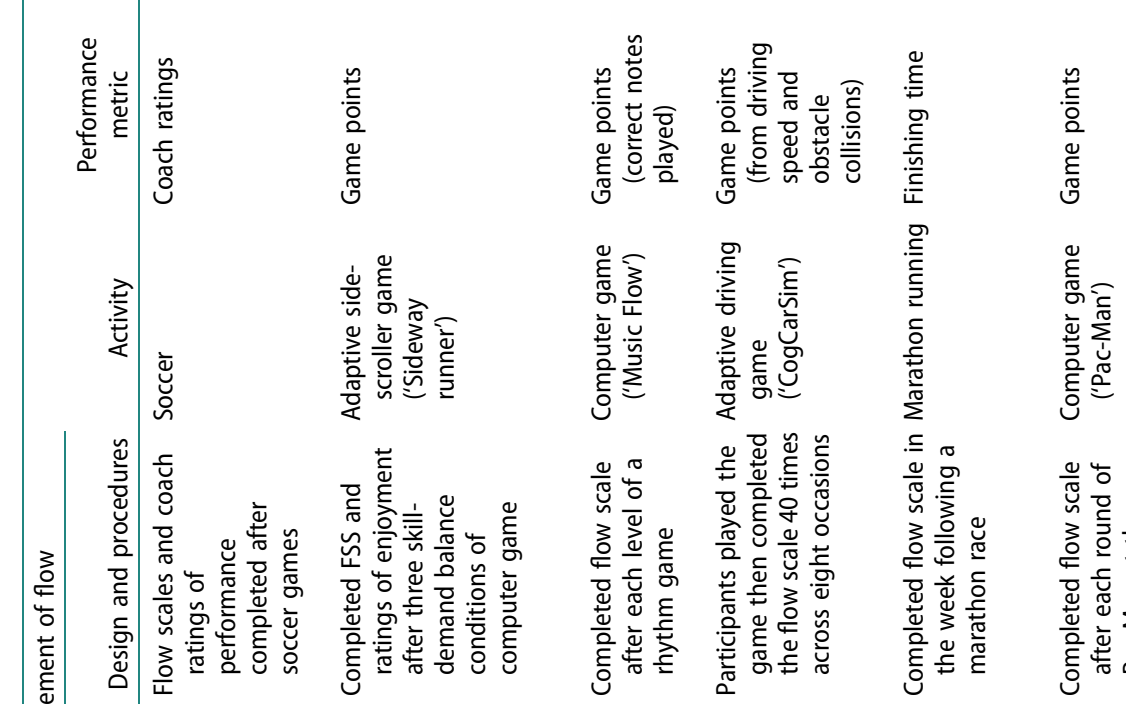

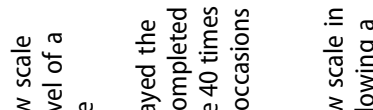

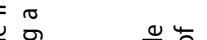

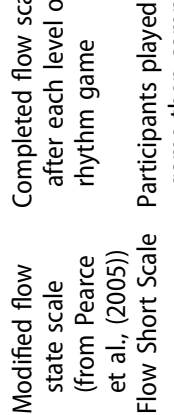

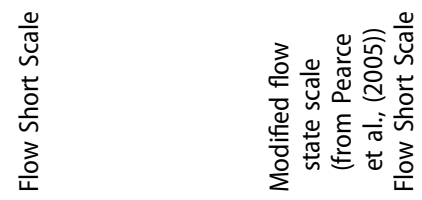

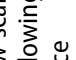
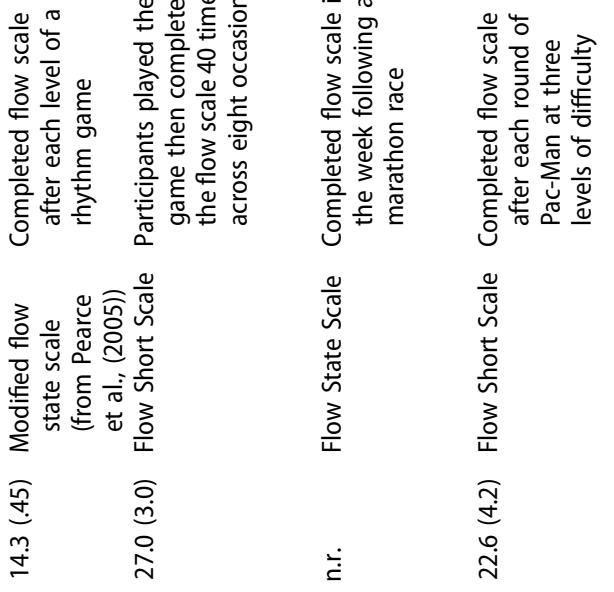

焉离离

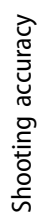

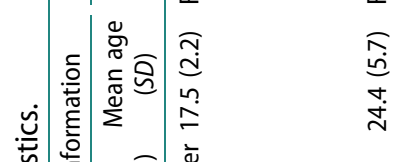

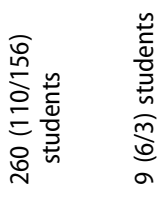

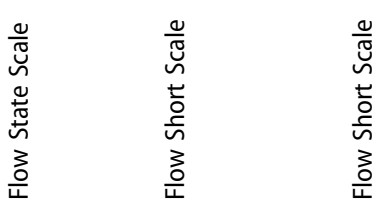




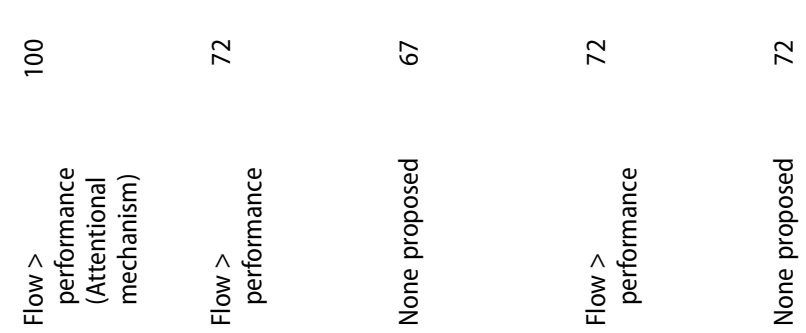

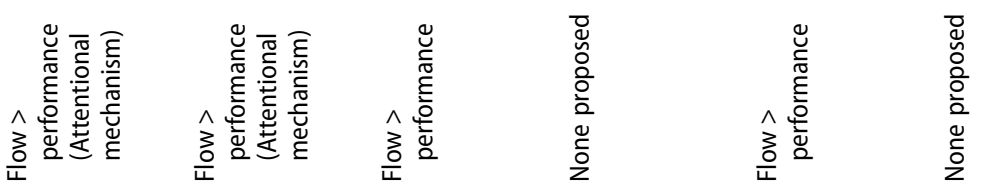

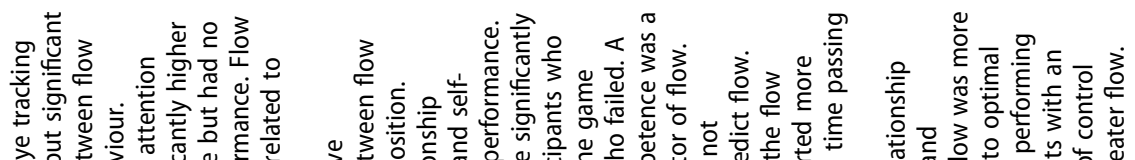

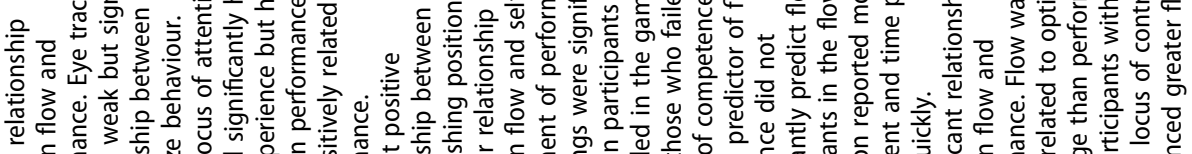

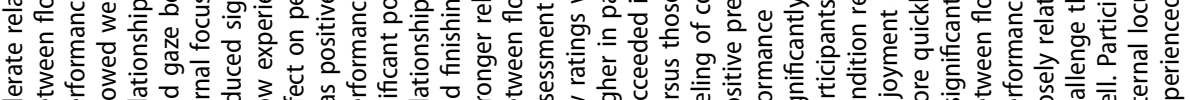

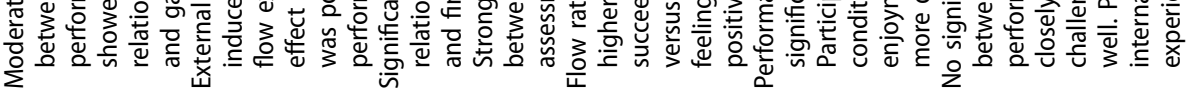
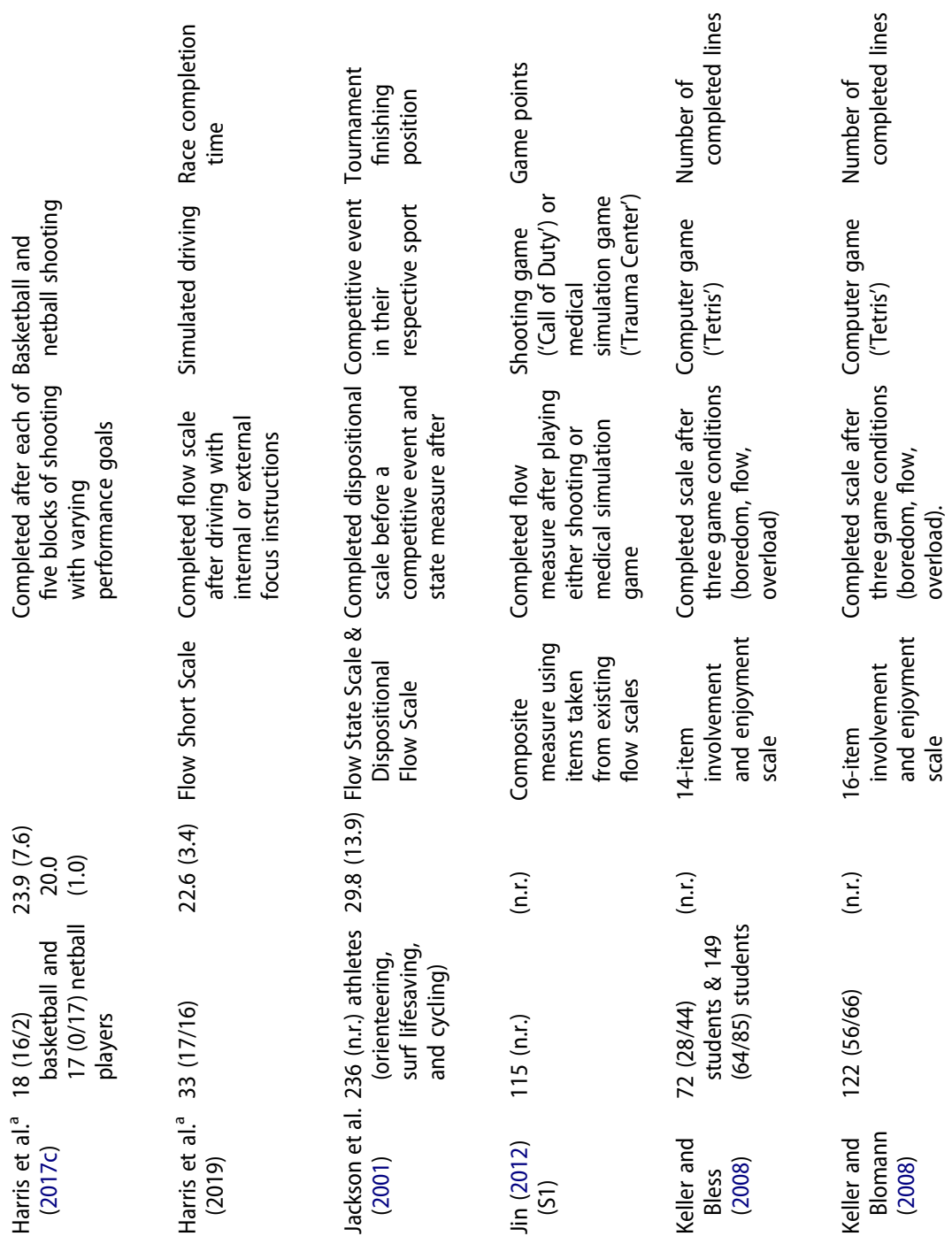


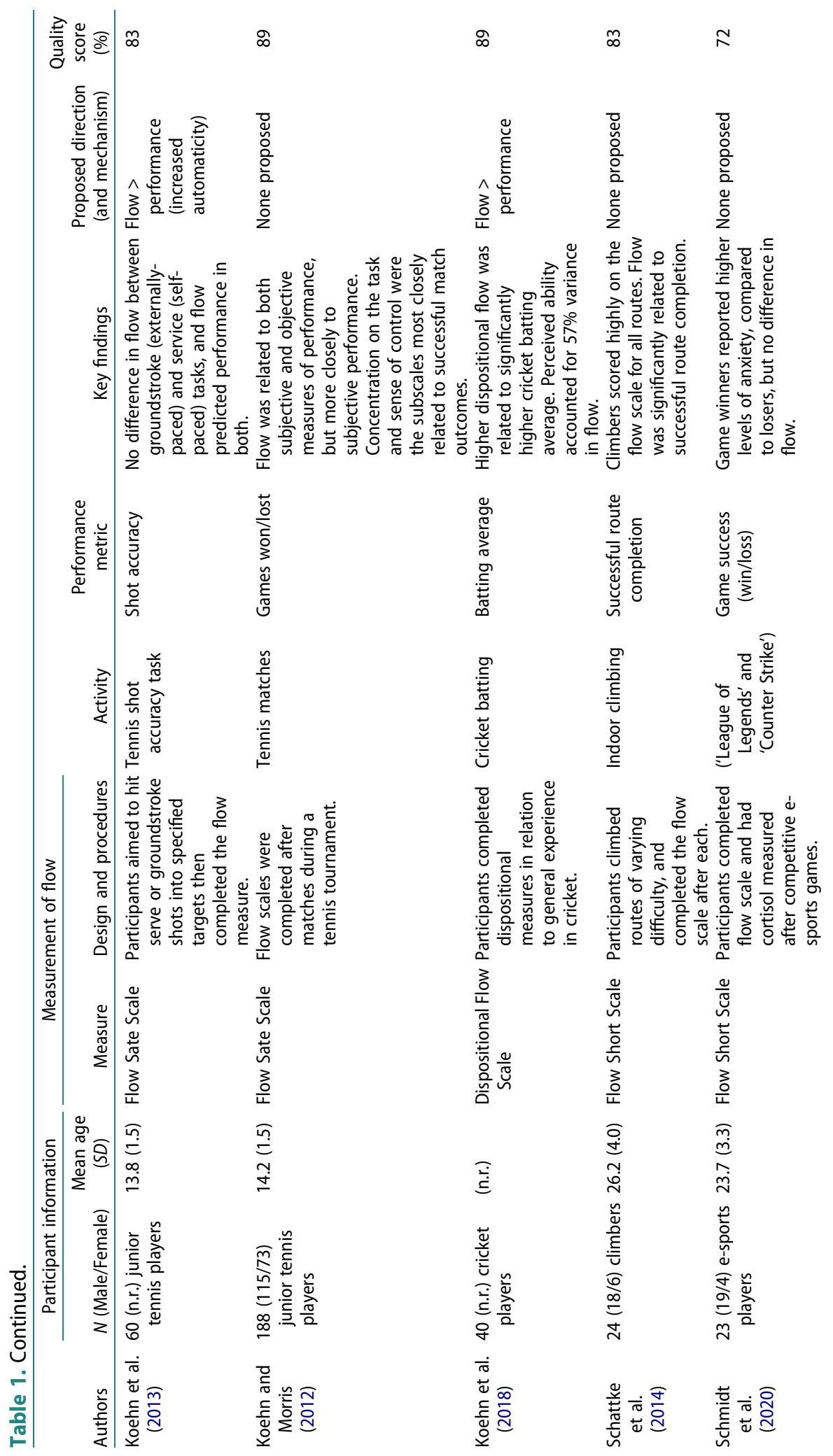


$\begin{array}{llll}6 & 6 & 2\end{array}$

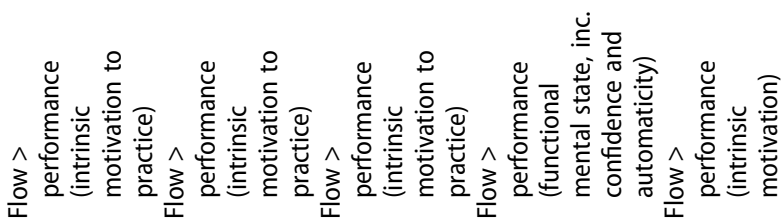

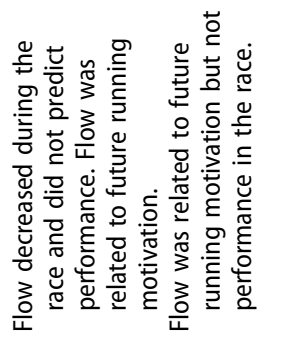

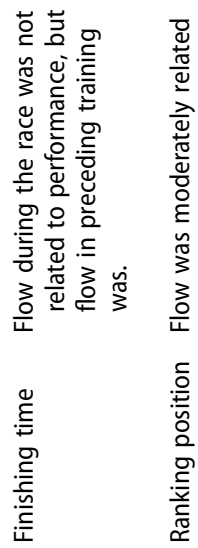
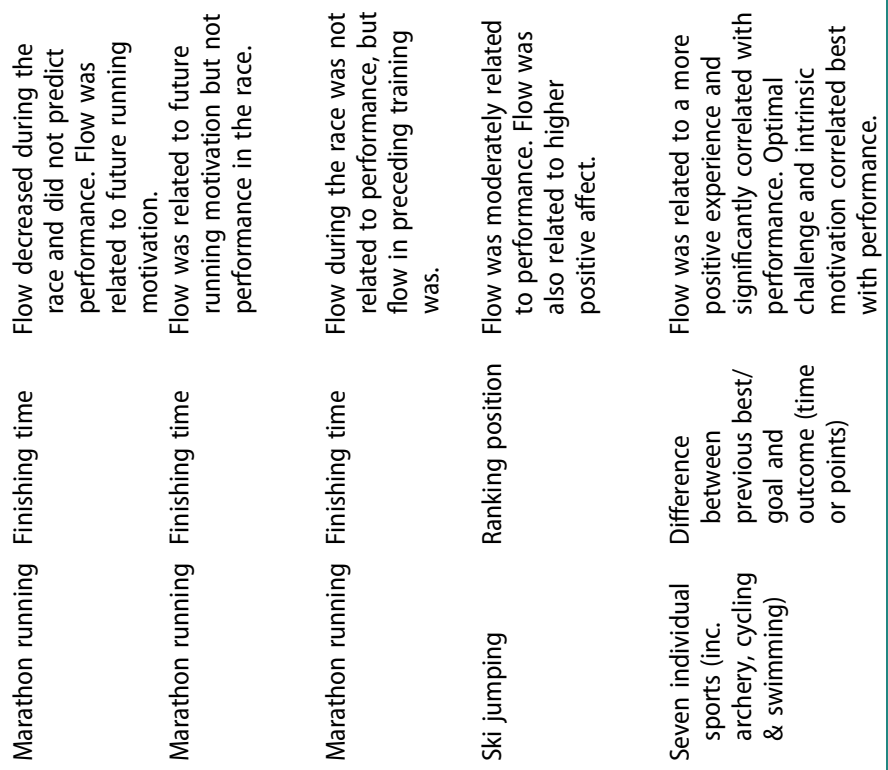

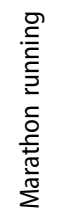
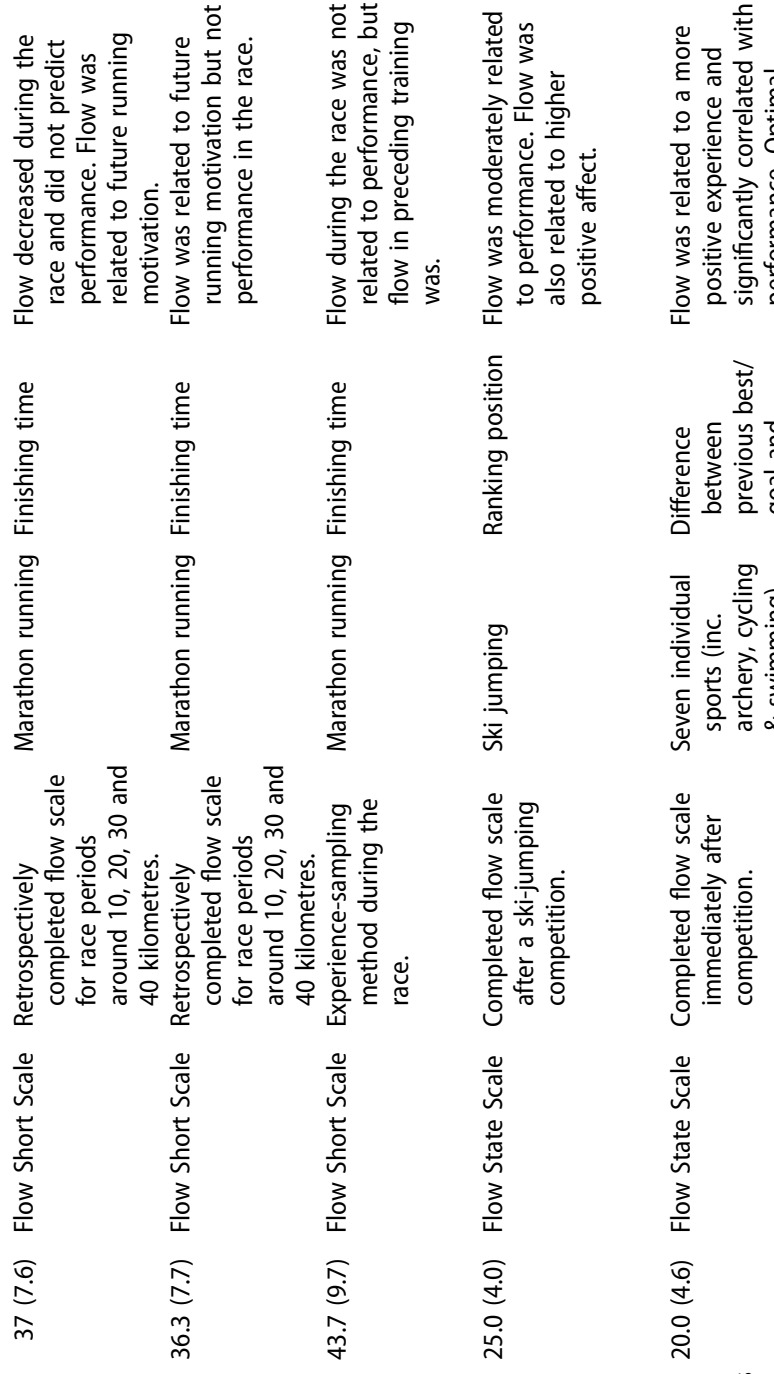

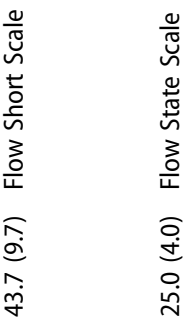
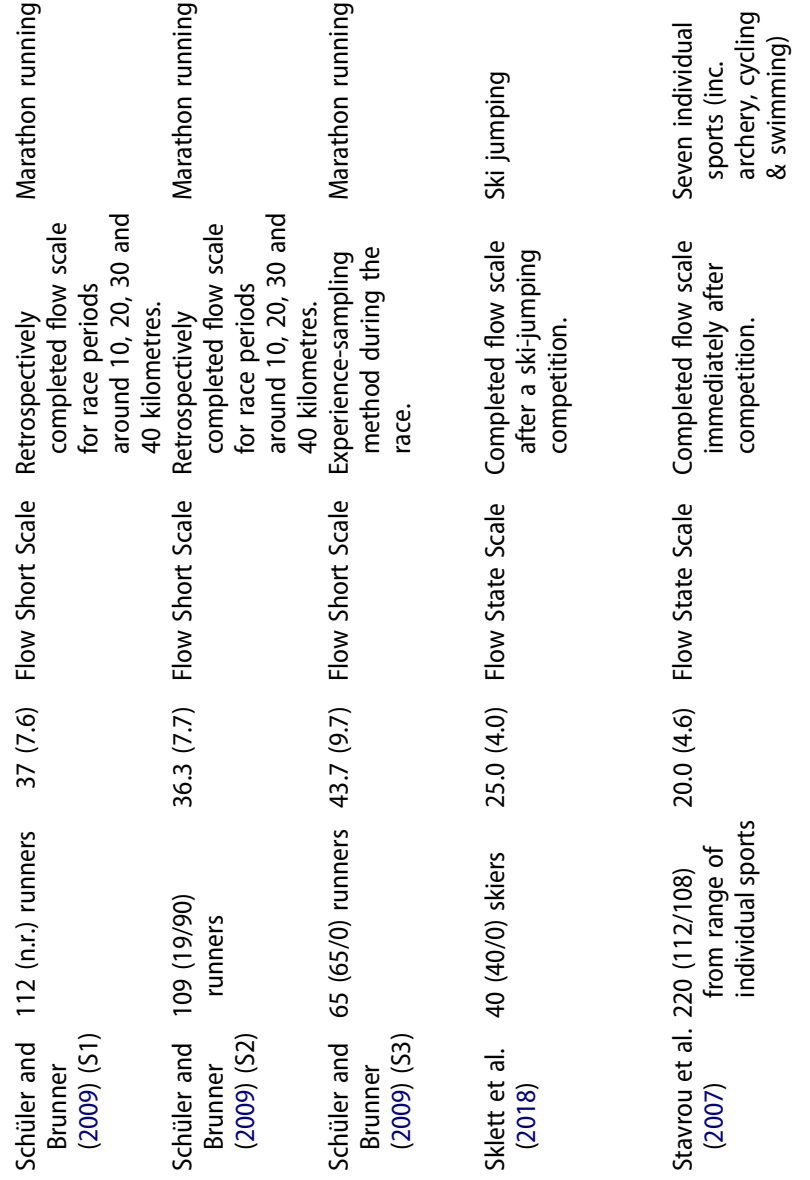

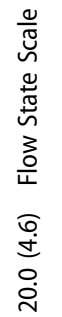

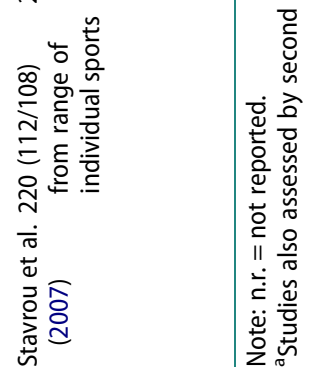


review, findings were summarised within three categories: measurement of flow; tasks used; and mechanisms and direction of causality (see Results for a textual summary). Popay et al. (2006) recommend that a narrative synthesis should seek to develop theoretical models of the mechanism of an effect. Therefore, we also detail some potential models of the flow-performance relationship that arose from the systematic review (see Figure 6).

\section{Results}

The electronic database search returned a total of 1288 records matching the search criteria. The removal of duplicates left 1070 unique items, with a further six articles added as a result of manual searching. Titles and abstracts were then screened for relevance to the inclusion criteria, which resulted in a further 1009 items being removed. Full texts of the remaining 67 articles were then obtained and screened for eligibility, with 47 items removed when they did not meet the inclusion and exclusion criteria. The main reasons for these full-text exclusions were: (i) the use of tasks that were outside the stated scope of the review; (ii) performance measures were self-reports of satisfaction with performance; (iii) there was no quantitative assessment of the flow-performance relationship. This resulted in a final sample of 20 relevant articles, featuring 22 relevant studies. $^{5}$

\section{Study characteristics}

An overview of the study characteristics (participants, design, measurement methods and key findings) is presented in Table 1. The sample consisted of 20 articles, all published between 2001 and 2020, with much of the work being published relatively recently (65\% of the reviewed studies were published since 2010). Of the $2521^{6}$ participants across all studies, 652 (25.9\%) were female, 912 (36.2\%) were male, and gender was not reported for 957 participants (37.9\%). The weighted mean age of samples in the review was 22.1 years. Of the 22 studies, nine focused on gaming and 13 used sport tasks. Flow was studied in more than 15 different sports and 10 different games, with marathon running the most common task (four studies). Most studies measured state flow $(n=21)$, one assessed dispositional flow, and one assessed both. The most commonly used methods of assessing flow were the Flow Short Scale (Rheinberg et al., 2003) $(n=10)$ and the Flow State Scale (Jackson \& Eklund, 2002) $(n=6)$. There were also two uses of the Dispositional Flow Scale (a trait level measure of flow; Jackson \& Eklund, 2002). In addition, there were four studies that used their own modified or composite measures (Chen \& Sun, 2016; Jin, 2012; Keller \& Bless, 2008; Keller \& Blomann, 2008)

\section{Tasks}

Effective tasks for studying flow generally need to satisfy the three proximal conditions; clear goals, immediate feedback and a balance of challenges and skills (Kawabata \& Mallett, 2011). Sport tends to deliver these naturally; the structure of sport provides clear goals and feedback, and performers tend to rise to a level of competition that provides an appropriate challenge. In the reviewed studies the sports tasks were soccer (Bakker et al., 2011), marathon running (Delrue et al., 2016; Schüler \& Brunner, 2009), 
basketball and netball (Harris et al., 2017c), tennis (Koehn et al., 2013; Koehn \& Morris, 2012), cricket (Koehn et al., 2018), climbing (Schattke et al., 2014), skiing (Sklett et al., 2018) and mixed sports (Jackson et al., 2001; Stavrou et al., 2007). Computer gaming is also well-suited to the study of flow, because not only are computer games designed to be highly absorbing (Kiili et al., 2012; Michailidis et al., 2018), but they allow the challenges of the task to be experimentally controlled. The approach of manipulating the demands of the game in order to provide tasks that are too easy, too hard and optimally challenging was a common method of manipulating flow in the gaming studies (Baumann et al., 2016; Engeser \& Rheinberg, 2008; Harris et al., 2019; Keller \& Bless, 2008; Keller \& Blomann, 2008). A wide range of gaming tasks was used, including Tetris (a block stacking game) (Keller \& Bless, 2008; Keller \& Blomann, 2008), simulated driving (Cowley et al., 2019; Harris et al., 2019) and Call of Duty (a first-person shooter) (Jin, 2012).

\section{Study quality}

The assessment of study quality indicated that the studies included in the review displayed a moderate to high degree of rigor. The scores ranged from $61 \%$ to $100 \%$, with a mean of $76.5 \%(S D=9.7)$. The most poorly addressed items were reporting of adherence to ethical standards and a priori determination of sample sizes (see Figure 1).

A number of systematic reviews and meta-analyses report that lower quality studies, and those with smaller sample sizes tend to report larger effects (Hempel et al., 2011). To assess whether small- and low-quality studies were likely to bias the results, correlation

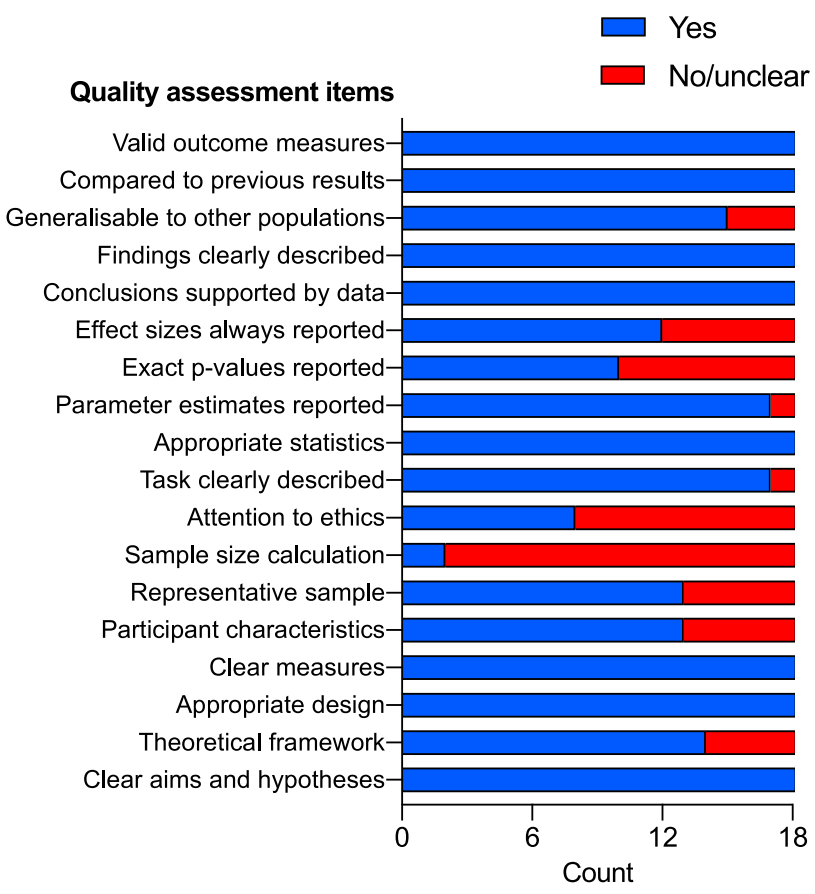

Figure 1. Quality assessment items and scores from the 18 included articles. 

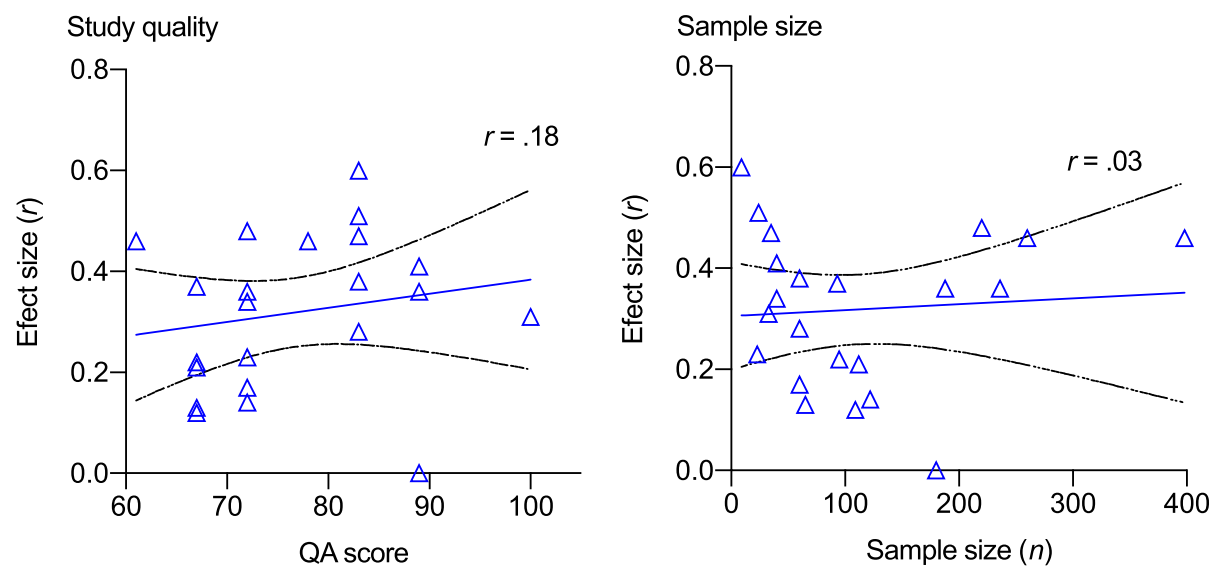

Figure 2. Scatter plots of the relationship between reported effect size and study quality (left) and sample size (right), with regression lines and $95 \%$ confidence intervals.

analyses were run between effect size and quality assessment score, and between effect size and sample size. There was no significant relationship between study quality and effect size $(r(20)=.18, p=.42)$, and no relationship between sample size and effect size $(r(20)=.03, p=.74)$, indicating low risk of bias in this regard (see Figure 2).

\section{Quantitative synthesis}

The results of the meta-analysis indicated that there was a reliable relationship between flow and performance across studies and tasks, $r=0.31,95 \% \mathrm{Cl}[0.24 ; 0.38]$ (see Figure 4). Based on the traditional interpretation of the $r$ value, this would equate to a

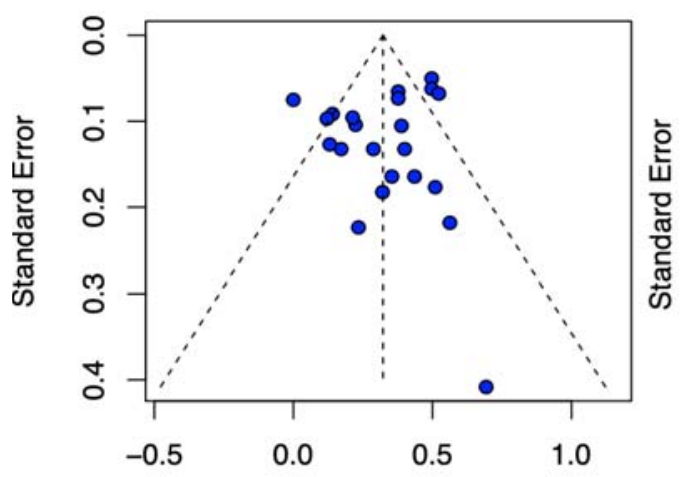

Fisher's z transformed correlation

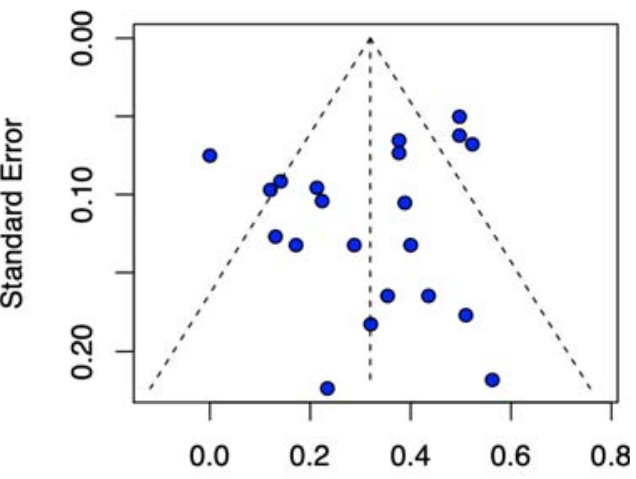

Fisher's z transformed correlation

Figure 3. Funnel plots showing effect estimates $(r)$ from individual studies against standard error. The outlying value in the left hand panel (bottom right) represents the study of Cowley et al. (2019) which had a small sample size. The right-hand panel illustrates the funnel plot with this outlier removed. The effect sizes and precisions illustrated by the remaining data points cluster within the funnel but are sparser to the lower left-hand corner, suggesting a possible publication bias away from studies with smaller effects and smaller samples. 


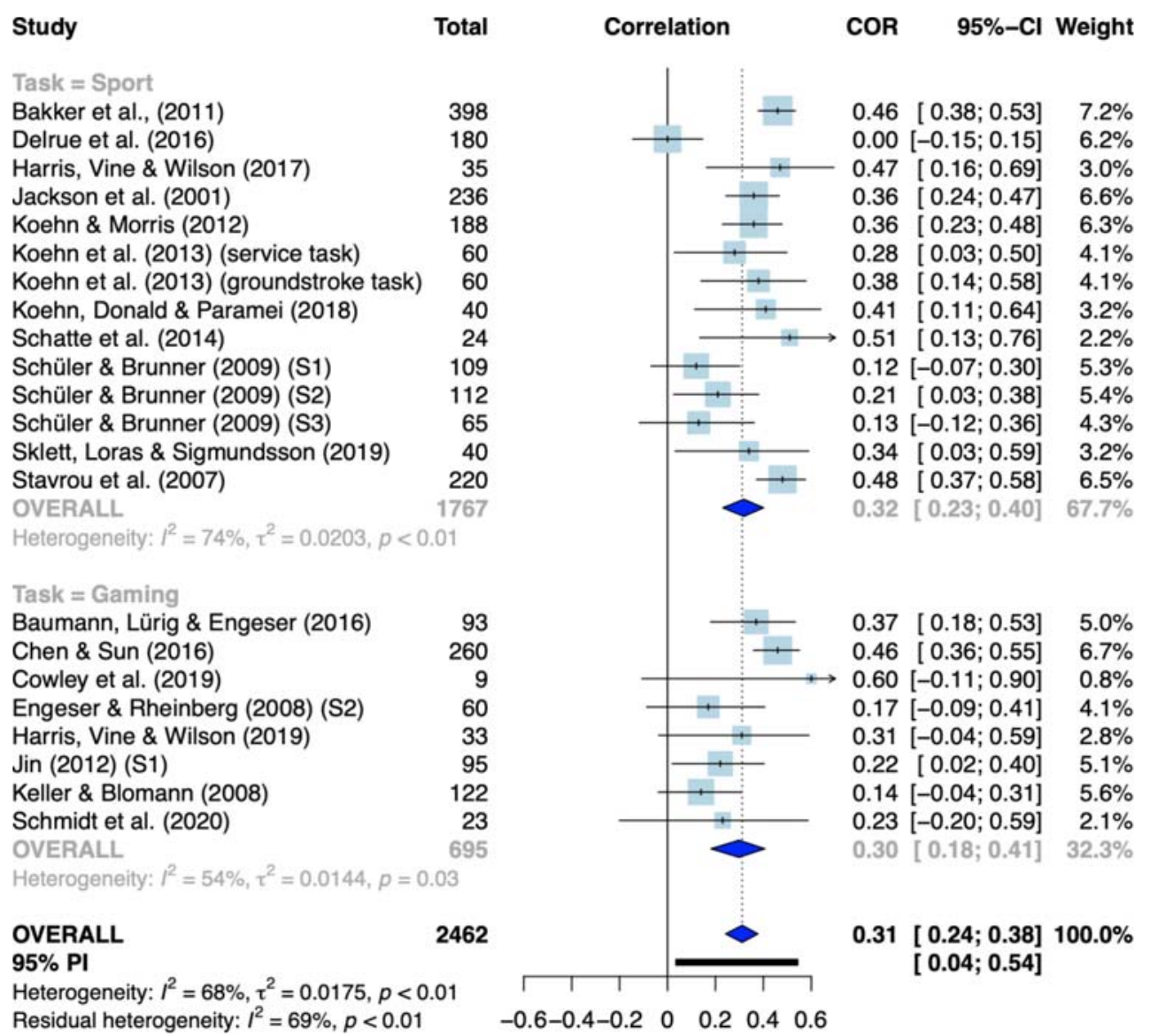

Figure 4. Forest plot of effect sizes ( $r$ ) from all studies included in the systematic review. The combined estimate and $95 \%$ confidence interval (blue diamond) indicates a reliable moderate-sized relationship between flow and performance. The size of the light blue squares indicates the weight of the study in the combined analysis (based on sample size). The plot also shows the prediction interval (Pl; thick black line), the range within which the point estimate of $95 \%$ of all future studies are likely to fall.

medium-sized effect (Cohen, 1988). The studies displayed a moderate to a high degree of heterogeneity $\left(I^{2}=68 \%\right)$ supporting the use of a random-effects model (Borenstein et al., 2009). Due to this heterogeneity, a subgroup analysis was performed by splitting studies into those which used a sport-based task, and those which used computer gaming. Heterogeneity was higher in the sport subgroup (74\%) compared to the gaming subgroup (54\%), which may reflect additional variance arising from the diverse range of sports studied. The effect sizes in the two subgroups were found to be similar, with $r=0.32,95 \% \mathrm{Cl}[0.23 ; 0.40]$ in sport and $r=0.30,95 \% \mathrm{Cl}[0.18 ; 0.41$ ] in gaming.

A common heuristic for identifying outliers in meta-analyses is to determine when the confidence interval of a reported effect does not cross that of the pooled estimate (Borenstein et al., 2009). An outlier analysis using this method indicated that two studies Bakker et al. (2011) and Delrue et al. (2016) - might be considered outliers. The 
Table 2. Results of the leave-one-out analysis.

\begin{tabular}{lccccc}
\hline Study left out & $r$ & Std. error & Cl Lower & Cl Upper & I2 \\
\hline Bakker et al. (2011) & 0.30 & 0.03 & 0.24 & 0.37 & 63.01 \\
Baumann et al. (2016) & 0.31 & 0.04 & 0.24 & 0.38 & 68.98 \\
Chen and Sun (2016) & 0.31 & 0.03 & 0.24 & 0.37 & 64.72 \\
Cowley et al. (2019) & 0.31 & 0.03 & 0.24 & 0.38 & 68.38 \\
Delrue et al. (2016) & 0.34 & 0.03 & 0.28 & 0.40 & 54.71 \\
Engeser and Rheinberg (2008) (S2) & 0.32 & 0.03 & 0.25 & 0.39 & 68.31 \\
Harris, Vine \& Wilson (2017) & 0.31 & 0.03 & 0.24 & 0.38 & 68.49 \\
Harris et al. (2019) & 0.32 & 0.03 & 0.25 & 0.38 & 69.14 \\
Jackson et al. (2001) & 0.31 & 0.04 & 0.24 & 0.38 & 67.96 \\
Jin (2012) (S1) & 0.32 & 0.04 & 0.25 & 0.39 & 68.56 \\
Keller and Blomann (2008) & 0.33 & 0.03 & 0.26 & 0.39 & 66.61 \\
Koehn and Morris (2012) & 0.31 & 0.04 & 0.24 & 0.38 & 68.36 \\
Koehn et al. (2013) (service task) & 0.32 & 0.04 & 0.25 & 0.39 & 69.17 \\
Koehn et al. (2013) (groundstroke task) & 0.31 & 0.04 & 0.24 & 0.38 & 69.08 \\
Koehn et al. (2018) & 0.31 & 0.04 & 0.24 & 0.38 & 68.97 \\
Schattke et al. (2014) & 0.31 & 0.03 & 0.24 & 0.38 & 68.34 \\
Schmidt et al. (2020) & 0.32 & 0.03 & 0.25 & 0.39 & 68.90 \\
Schüler and Brunner (2009) (S1) & 0.33 & 0.03 & 0.26 & 0.39 & 66.32 \\
Schüler and Brunner (2009) (S2) & 0.32 & 0.04 & 0.25 & 0.39 & 68.28 \\
Schüler and Brunner (2009) (S3) & 0.32 & 0.03 & 0.26 & 0.39 & 67.66 \\
Sklett et al. (2018) & 0.31 & 0.04 & 0.25 & 0.38 & 69.19 \\
Stavrou et al. (2007) & 0.30 & 0.03 & 0.24 & 0.37 & 64.22 \\
\hline
\end{tabular}

removal of these two studies, however, made very little difference to the pooled effect estimate $(r=0.32,95 \% \mathrm{Cl}[0.25 ; 0.38])$, and neither of the studies diverged excessively from the pooled estimate. Hence all studies were retained in the meta-analysis to preserve the richness of the data. The alternative analysis of the data set without potential outliers is available in the supplementary materials (https://osf.io/3hfcu/).

The results of the robustness checks indicated that no studies included in the metaanalysis had a disproportionate effect on the overall result. The pooled effect estimates in the leave-one-out analysis ranged from 0.30 to 0.34 with a standard deviation of 0.008 , suggesting that the removal of any single study had little effect (see Table 2). The results of combinatorial meta-analyses indicate that there was no distinct clustering of data points that might indicate that the inclusion/exclusion of particular studies or groups of studies had a distorting influence on the estimate. The 2,097,152 iterations of the combinatorial meta-analyses are presented as Graphical Display of Study Heterogeneity (GOSH) plots in Figure 5 . The plots illustrate effect sizes plotted against the $I^{2}$ for all possible combinations of studies.

\section{Narrative synthesis}

\section{Methods of measuring flow}

All studies in the systematic review used flow questionnaires to measure flow experience. While psychophysiological methods were employed in three studies (Harris et al., 2017c, 2019; Schmidt et al., 2020) they were used alongside self-report measures of flow. There are currently no objective measures that can be used in lieu of self-report (i.e. questionnaires, interviews or experience sampling ${ }^{7}$ ), and such an approach would be conceptually questionable due to the fact that the flow experience is inherently defined by its phenomenology. 

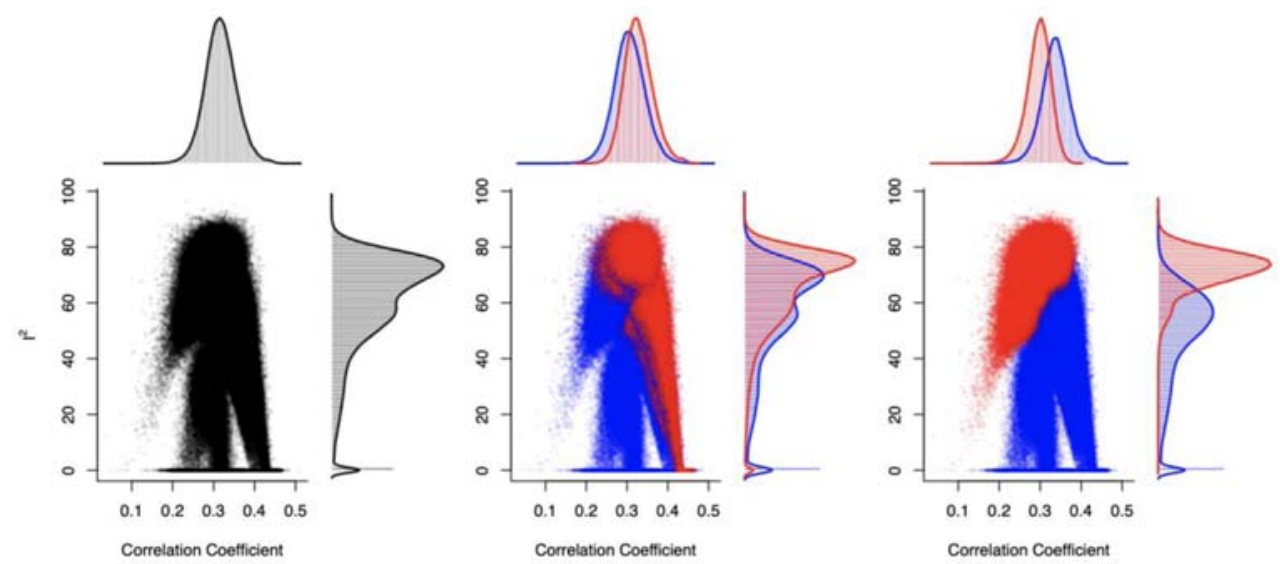

Figure 5. GOSH plots illustrating the results of the combinatorial meta-analyses in the form of a scatter plot of effect size estimates against heterogeneity for all possible combinations. The plot show results for all included studies (Left), and with (red) and without (blue) the potential outlier studies of Bakker et al. (2011) (Center) and Delrue et al. (2016) (Right). The marginal distributions indicate that these two studies introduce some heterogeneity (particularly Delrue et al.) but do not bias the overall effect estimate.

The questionnaires used essentially reflected two primary measures of flow. Firstly, the Flow State Scale and the Dispositional Flow Scale (and the updated versions the Flow State Scale-2 and the Dispositional Flow Scale-2) (Jackson \& Eklund, 2002) are both

a)

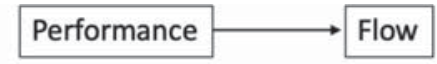

b)

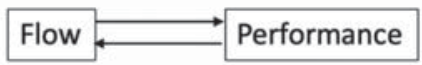

c)

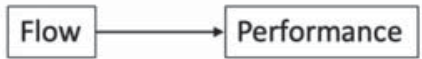

c.1)

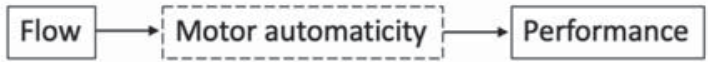

c. 2)

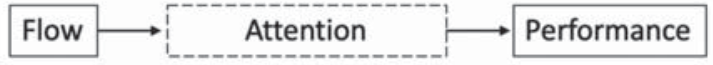

c.3)

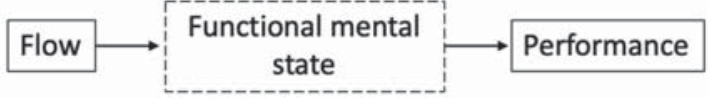

c.4)

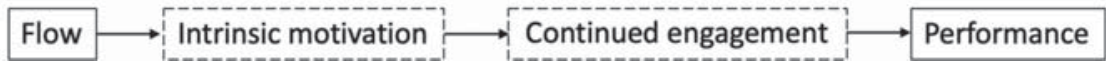

Figure 6. Schematic diagram of the flow-performance relationships and proposed mechanisms arising from the systematic review. No studies focused directly on relationship a or b but both were acknowledged as possible relationships (Jin, 2012; Schattke et al., 2014). Relationship c was the most common and discussed explicitly in at least 11 articles. Of the articles describing relationship c, a number of specific pathways were outlined: c.1 was proposed in Koehn et al. (2013); c.2 was proposed in two studies by Harris et al. (2017c, 2019); c.3 was proposed in Engeser and Rheinberg (2008) and Sklett et al. (2018), and c.4 was proposed in the studies of Schüler and Brunner (2009). In relation to the two routes for performance enhancement proposed by Landhäußer and Keller (2012), c.1, c.2, and c.3 relate to the direct route, and c.4 relates to the indirect effect of motivation. 
based on the nine dimensions of flow outlined by Csikszentmihalyi $(1975,2014)$, with each of the questions in these scales mapping onto one of the dimensions, creating a nine-dimensional scale. The difference between the two is that the Flow State Scale refers to flow in an immediately preceding activity, while the Dispositional Flow Scale refers to an activity more generally. Secondly, the Flow Short Scale (Rheinberg et al., 2003) is a shorter measure that does not explicitly map onto the nine flow dimensions, although they remain an important foundation of the measure. The Flow Short Scale reflects Rheinberg's (2008) conceptualisation of flow, which does not include autotelicity, and loads onto two underlying dimensions of fluency of performance and absorption. The Flow Short Scale has tended to be more widely used within gaming studies and those employing psychophysiological measures, and was used in eight of the reviewed studies, five in gaming (Baumann et al., 2016; Cowley et al., 2019; Engeser \& Rheinberg, 2008; Harris et al., 2019; Schmidt et al., 2020) and three in sport (Harris et al., 2017c; Schattke et al., 2014; Schüler \& Brunner, 2009). The Flow State Scale and Dispositional Flow Scale have been more prominent within sport research and were used in eight studies, all of which used sport-based tasks (Bakker et al., 2011; Delrue et al., 2016; Jackson et al., 2001; Koehn et al., 2013, 2018; Koehn \& Morris, 2012; Sklett et al., 2018; Stavrou et al., 2007).

In addition to these measures, four studies used methods of measurement that were not established instruments. For instance, Keller and Bless (2008) and Keller and Blomann (2008) used a questionnaire measure of involvement and enjoyment as a proxy measure of flow, reasoning that it was the most important element of the flow experience. This poses something of a problem, because it creates a lack of consistency with other measures, and fails to address all aspects of the experience, such as concentration. Similarly, Chen and Sun (2016) and Jin (2012) both used bespoke measures derived from existing flow scales.

\section{Mechanisms and direction of causality}

As discussed previously, two routes for a flow-performance relationship have previously been proposed in the literature (Landhäußer \& Keller, 2012); one through a direct performance enhancement because of the functional mental state occurring during flow, and one via enhanced motivation to practise and reengage with the task. All studies focused on the former mechanism, bar the three marathon running studies of Schüler and Brunner (2009) that examined how flow in a race could affect future motivation to train. While flow during marathons was not found to be closely related to better performance outcomes, it was predictive of the intention to re-engage in running. Additionally, flow during training was a significant predictor of marathon performance. The authors suggest this is because those who experienced flow during training were also likely to train more frequently.

The studies exhibited a degree of variation in the way the flow-performance relationship was described, and while the relationship was commonly acknowledged it was often described in rather vague terms. A number of studies bypassed the issue by avoiding predictions about time-course or direction, and just referred to a relationship between the two (Jin, 2012; Keller \& Blomann, 2008; Schattke et al., 2014). Several others were, however, much more specific about flow having performance-enhancing effects (Jackson et al., 2001; Koehn et al., 2013, 2018; Stavrou et al., 2007) and that flow could 
lead to performance enhancements (i.e. relationship c in Figure 6). There was a relatively little critical reflection on the causal direction of this relationship across the studies.

There was also a little direct examination of the mechanisms through which flow might enhance performance. This partly reflects the fact that many of the articles were not primarily concerned with performance, and instead reported on the flow-performance relationship as a secondary objective. Some, however, did propose explanations for the flow-performance relationship, even if it was not directly measured. The mechanisms that were explicitly discussed are represented in Figure 6. For instance, Sklett et al. (2018) and Engeser and Rheinberg (2008) both explained the flow-performance relationship as a result of the highly functional mental state that arises during flow (relationship c.3 in Figure 6), but neither was more specific about exact mechanisms and what functional features of flow might be most important.

In a more direct examination of the flow-performance relationship, Koehn et al. (2013) explicitly referred to Dietrich's hypofrontality hypothesis to account for their findings (relationship c.1, Figure 6). Koehn and colleagues suggested that an increased automaticity of performance arising from a reduction in prefrontal activation could be responsible for the performance-enhancing effects of flow. In a related vein, two studies by Harris et al. (2017c, 2019) also appealed to attentional mechanisms. Focused concentration is a central feature of the flow experience, and could account for performance enhancements, particularly in sport (Mann et al., 2007; Memmert, 2009) and Esports (Campbell et al., 2018). In their first study, Harris et al. (2017c) found that in a basketball and netball shooting task flow was significantly, albeit weakly, associated with more goal-directed control of visual attention, which could be responsible for performance improvements. Additionally, Harris et al. (2019) demonstrated that an external focus of attention, which has established benefits for motor skill execution (Wulf, 2013), resulted in a greater flow experience, suggesting that the type of task-directed attention typical of flow could be a mechanism for performance benefits.

None of these studies, however, provided particularly compelling evidence for a mechanism, such as could be provided by statistical mediation of a flow-performance relationship by a third factor. Perhaps the most convincing evidence comes from the more longterm benefits of flow described by Schüler and Brunner (2009), who found flow was related to enhanced motivation to train, and better future performances. Consequently, the overall evidence for a mechanism was weak, partly due to a lack of focus on this issue in the extant literature, and partly due to methodological deficiencies, an issue to which we return in the discussion.

\section{Discussion}

The purpose of the present work was to critically review and synthesise the available evidence for a relationship between the state of flow and improved task performance. There has been particular interest in flow from researchers in the sports and gaming domains because of the possibility for performance enhancement. Yet, despite frequent discussion of links between flow and performance (Aherne et al., 2011; Jackson \& Csikszentmihalyi, 1999; Swann et al., 2017), the nature of the relationship is not well understood. Further, there has been no systematic review of the evidence for the putative relationship. Consequently, we aimed to address the following research questions: (i) is there reliable 
evidence for a relationship between flow and performance?; (ii) what is the nature of this relationship (i.e. direction)?; (iii) what is the quality of the research in this field?; and (iv) what evidence is there regarding mechanisms through which flow may enhance performance?

\section{Summary of findings}

\section{Is there reliable evidence for a relationship between flow and performance?}

The primary finding of the systematic review and meta-analysis was a small to moderate relationship between flow and improved performance across the included studies. This effect was consistent across gaming and sport tasks alike, and no articles reported negative relationships. Consequently, there does appear to be a reliable relationship between flow and performance. It is worth emphasising, however, that a considerable proportion of performance variance was not accounted for by flow.

\section{What is the nature of this relationship (i.e. direction of causality)?}

The studies included in the review were not able to provide any empirical evidence regarding the direction of the flow-performance relationship. An effect whereby flow leads to improved performance was the most commonly discussed, yet the inverse relationship - where good performance creates the experience of flow - was also proposed, as was a reciprocal relationship. Crucially, although a causal effect of flow was the most commonly discussed effect, no research designs were able to actually test this directionality. The vast majority of the reported results were correlational, making discussions about causality problematic. One of the reasons for this is that the flow-performance relationship was often not the focus of the studies and was reported as a secondary analysis. Another issue is the difficulty with manipulating flow in order to draw causal inferences, an issue we return to later.

\section{What is the quality of the research in this field?}

The quality assessment scores indicated that the studies in this sample were of a reasonably good quality (see Figure 1). The sample sizes across the studies were generally quite large, and no relationship between sample size and effect size was found, indicating that it is unlikely that lack of power biased the findings. The funnel plots (Figure 3) suggest that there may have been some publication bias with articles reporting smaller effects and smaller samples more likely to remain unpublished. Additionally, no studies reported a negative relationship between performance and flow, which might also suggest a publication bias. Despite the overall quality of the research in relation to the assessment items, the design of most studies - which correlated post-event flow questionnaires with the preceding performance - was not sufficient to answer questions about causality. Future work should look to experimental designs that manipulate factors of interest to more effectively address questions about cause and effect.

\section{What evidence is there regarding mechanisms through which flow may enhance performance?}

The reviewed studies were not able to provide any conclusive results regarding intervening mechanisms. Several studies noted the 'functional mental state' during flow as a 
reason for performance benefits. Improved attentional control and motor automaticity were also cited as possibilities. Yet these mechanisms were often not measured, so limited conclusions can be drawn. It is highly plausible that the functional mental state that arises during flow - including focused attention, confidence, reduced self-awareness - will indeed facilitate performance (Swann et al., 2017), but presently there is insufficient empirical data to demonstrate that these sorts of changes are enhancing performance.

\section{Conceptual and methodological issues}

A number of conceptual and methodological issues relating to the flow-performance relationship became apparent during the review. Firstly, a major limitation with all research in this area is the difficulty with rejecting reporting bias as the source of the flow-performance relationship; an issue that stems from the use of correlational approaches as well as the methodological challenges of manipulating flow. Sports performers commonly attribute exceptional performances to being in flow, but this kind of retrospective attribution is fraught with reporting biases. The psychological aftereffects of a good performance could easily induce athletes to report a range of positive experiences suggestive of flow. Indeed, a study by Brewer et al. (1991) demonstrated that when participants were given bogus positive feedback following a pursuit rotor task they rated themselves as having been more focused and more confident during the task, regardless of their actual performance. This finding suggests that even immediate post-event assessment may be strongly biased by the outcome. While it seems unlikely that the entirety of the flow-performance relationship could be explained by a reporting bias, it is nonetheless hard to dispel.

A second possible confound in many studies is the issue of a performer's baseline ability. Later versions of the flow model have emphasised that flow is more likely when skills and challenges are both high, and not just in balance (Nakamura \& Csikszentmihalyi, 2002). Studies have generally not controlled for prior or 'normal' performance, so if the flow is more likely in more skilled performers then a flow-performance relationship could emerge for this reason alone (i.e. better performers report higher flow, creating an apparent correlation between flow and performance). One article from the review, Cowley et al. (2019), suggested that this is, however, not the case. In a longitudinal design, Cowley and colleagues showed that there was no change in the experience of flow as participants acquired expertise in a driving game. Rather, the balance between the challenge of the task and the skill of the performer remained the determining factor. Nonetheless, future studies may still wish to control for baseline abilities.

A more fundamental consideration for this research area is whether a focus on outcomes misses the point of the flow concept. Csikszentmihalyi expressed concern that 'as soon as the emphasis shifts from the experience per se to what you can accomplish with it, we are back in the realm of everyday life ruled by extrinsic considerations' (Csikszentmihalyi \& Csikszentmihalyi, 1992, p. 374). A more pragmatic view has generally been taken within sport psychology, and flow has been adopted into theories of enhanced performance (Swann et al., 2017). Additionally, flow has been used as a proxy for performance or a method for improving performance within interventions (Aherne et al., 2011; Nicholls et al., 2005). Yet, to retain the authenticity of the original concept it may be important to avoid amalgamating flow and performance too heavily, in order to keep sight of other important facets of a complex experience (e.g. enjoyment and motivation). 


\section{Limitations}

A limitation of the current work is the focus on quantifying the flow-performance relationship in a meta-analysis. Flow research lends itself to in-depth analysis of the experience of athletes, hence there is important work that has used qualitative methods to examine flow and performance (Bernier et al., 2009; Jackson, 1992; Swann et al., 2016). Several intervention studies with $\mathrm{N}$-of-1 designs were also identified during the search process. This body of work provides useful insight into the phenomenology of flow experiences but was not appropriate for current purposes as it did not quantify the flow-performance relationship and could be prone to retrospective and common methods biases (Podsakoff et al., 2003).

\section{Future research directions}

Over 20 years ago, Jackson and Kimiecik (2008) advised that 'Although a close relationship between flow and peak performance is apparent, more research is needed to examine the specifics of the flow-peak performance link'. Firstly, the findings of this review have highlighted that the relationship is rather more modest than Jackson and Kimiecik assumed. The quantitative synthesis revealed only a moderate relationship, suggesting that flow and performance only partly overlap ( $10 \%$ shared variance). Secondly, and perhaps more importantly, the narrative synthesis showed that very little research has purposefully examined the specifics of the flow-performance link. Therefore, key questions about the direction of causality and mechanisms of effect remain to be answered.

Researchers have previously identified that the study of flow in sport is, in general, lacking answers to questions about the direction of effects and plausible models for testing hypotheses (Moran \& Toner, 2017; Swann et al., 2018). The findings of the present review support these contentions in relation to flow and performance enhancement. To address these shortcomings, clear predictions about directional effects and mechanisms of action are needed (Swann et al., 2018). An experimental approach may therefore be required to manipulate factors of interest and identify causal effects (Imai et al., 2011; Landhäußer \& Keller, 2012). Ideally, research to examine the flow-performance relationship would manipulate flow to observe changes in performance. Unfortunately, as flow is an experience, this cannot be achieved directly. Previous attempts have largely focused on controlling the challenge-skill balance to elicit variations in flow (Fong et al., 2015), but any subsequent performance effects are confounded by the manipulation of task difficulty. Future research, then, should seek to manipulate factors like performance feedback to examine directionality (Brewer et al., 1991), and establish whether the flow-performance relationship exists outside of any glow effects from positive outcomes. Moreover, there is a need to measure intervening mechanisms. This endeavour will suffer from some of the same methodological challenges as determining the direction of causality. However, the first steps in this direction are straightforward: clear hypotheses about the processes involved and direct measurement techniques to assess whether changes in predicted variables mediate the flow-performance link.

Other important considerations in future work may include the adoption of more frequent assessment of flow, such as measurements taken during performance, to reduce retrospective distortions (Jackman et al., 2019). It is also important to conduct work 
that adopts established flow measurement instruments instead of using bespoke and modified versions, to facilitate comparisons between studies and synthesis of findings. Future researchers may also wish to examine the separate dimensions of flow that most strongly relate to performance to better understand the relationship. While performance may have a consistent correlation with overall flow scores, this could be driven by some factors (e.g. the challenge-skill balance) more than others and separating questionnaire dimensions may help to disentangle the effect. Finally, improvements in study quality across this research area could be achieved with relatively simple measures such as a priori power calculations, pre-registration, full reporting of statistics and effect sizes, and more thorough descriptions of participant characteristics and methods of recruitment.

\section{Conclusions}

While it seems highly likely that flow, and its accompanying changes, would provide an abundance of benefits for performance, the evidence to date cannot, unfortunately, support this conclusion. In this review, we have demonstrated that across a number of sporting and gaming tasks, flow exhibited a consistent relationship with performance. Yet the inherent challenges of this field of study, and shortcomings of existing research, mean that we can neither be sure about how flow benefits performance or even the direction of the relationship. Consequently, the inclusion of flow in theories of performance and within performance interventions seems premature. Flow may provide an exciting opportunity to understand instances of excellent performance, but considerable work is still required to properly understand the nature of this relationship.

\section{Notes}

1. While physiological stress is somewhat elevated, most likely exhibiting an inverted-U relationship with flow (Peifer et al., 2014), cognitive elements of anxiety, like worry, appear to be absent.

2. Brain imaging findings have generally indicated that widespread prefrontal deactivation during flow is an oversimplification, although a persistent inhibition of self-referential processing in the medial PFC does appear to be a feature of flow (see Harris et al. (2017a) for a review of the neural mechanisms of flow).

3. Sport was defined as activities involving both physical exertion and skill during which an individual or a team competes against another.

4. The study of Keller and Bless (2008) was excluded from the quantitative synthesis because, while the flow-performance relationship was assessed, the analysis was not reported in sufficient detail to enable the calculation of an effect size (they did report a non-significant relationship). Sklett et al. (2018) report different factors within flow rather than an overall score but describe 'flow-focus' as the primary measure, so we report the relationship of this factor with performance.

5. There were several articles reporting multiple experiments. Experiments were assessed on an individual basis and only the studies matching the search criteria were included.

6. Note: this figure includes participants from all studies, whereas one study could not be included in the meta-analysis, so only 2462 participants were part of the meta-analysis.

7. Experience sampling is a longitudinal method used in much of the early flow research where participants are cued to report on their experience (what they are doing and how it feels) at various intervals during the day. 


\section{Disclosure statement}

No potential conflict of interest was reported by the author(s).

\section{Funding}

DH was supported by a Royal Academy of Engineering UKIC Fellowship.

\section{Data availability}

All relevant data and code is available online from https://osf.io/3hfcu/

\section{Authors' CRediT contributions}

DH: Conceptualization; Data curation; Formal Analysis; Writing - original draft. KA: Conceptualization; Investigation; Formal Analysis; Writing - review \& editing. SV: Conceptualization; Investigation; Writing - review \& editing. MW: Conceptualization; Investigation; Writing - review \& editing.

\section{ORCID}

David J. Harris (1) http://orcid.org/0000-0003-3880-3856

Kate L. Allen (1) http://orcid.org/0000-0002-0870-7209

Samuel J. Vine (1) http://orcid.org/0000-0001-9329-1262

Mark R. Wilson (1) http://orcid.org/0000-0001-8145-6971

\section{References}

Aherne, C., Moran, A. P., \& Lonsdale, C. (2011). The effect of Mindfulness training on Athletes' flow: An initial investigation. The Sport Psychologist, 25(2), 177-189. https://doi.org/10.1123/tsp.25.2. 177

Bakker, A. B., Oerlemans, W., Demerouti, E., Slot, B. B., \& Ali, D. K. (2011). Flow and performance: A study among talented Dutch soccer players. Psychology of Sport and Exercise, 12(4), 442-450. https://doi.org/10.1016/j.psychsport.2011.02.003

Baumann, N., Lürig, C., \& Engeser, S. (2016). Flow and enjoyment beyond skill-demand balance: The role of game pacing curves and personality. Motivation and Emotion, 40(4), 507-519. https://doi. org/10.1007/s11031-016-9549-7

Beedie, C. J., Terry, P. C., \& Lane, A. M. (2000). The profile of mood states and athletic performance: Two meta-analyses. Journal of Applied Sport Psychology, 12(1), 49-68. https://doi.org/10.1080/ 10413200008404213

Bernier, M., Thienot, E., Codron, R., \& Fournier, J. F. (2009). Mindfulness and acceptance approaches in sport performance. Journal of Clinical Sport Psychology, 3(4), 320-333. https://doi.org/10.1123/ jcsp.3.4.320

Borenstein, M., Hedges, L. V., Higgins, J. P., \& Rothstein, H. (2009). Introduction to meta-analysis. John Wiley \& Sons.

Boudreau, P., Mackenzie, S. H., \& Hodge, K. (2020). Flow states in adventure recreation: A systematic review and thematic synthesis. Psychology of Sport and Exercise, 46, 101611. https://doi.org/10. 1016/j.psychsport.2019.101611

Brewer, B. W., Van Raalte, J. L., Linder, D. E., \& Van Raalte, N. S. (1991). Peak performance and the perils of retrospective introspection. Journal of Sport and Exercise Psychology, 13(3), 227-238. https://doi.org/10.1123/jsep.13.3.227 
Campbell, M. J., Toth, A. J., Moran, A. P., Kowal, M., \& Exton, C. (2018). Esports: A new window on neurocognitive expertise? Progress in Brain Research, 240, 161-174. https://doi.org/10.1016/bs. pbr.2018.09.006

Chen, L.-X., \& Sun, C.-T. (2016). Self-regulation influence on game play flow state. Computers in Human Behavior, 54, 341-350. https://doi.org/10.1016/j.chb.2015.08.020

Cohen, J. (1988). Statistical power analysis for the behavioral sciences, 2nd ed. Erlbaum.

Cowley, B. U., Palomäki, J., Tammi, T., Frantsi, R., Inkilä, V.-P., Lehtonen, N., Pölönen, P., Vepsäläinen, J., \& Lappi, O. (2019). Flow experiences during visuomotor skill acquisition reflect deviation from a power-law learning curve, but not overall level of skill. Frontiers in Psychology, 10. https://doi.org/ 10.3389/fpsyg.2019.01126

Cseh, G. M., Phillips, L. H., \& Pearson, D. G. (2015). Flow, affect and visual creativity. Cognition and Emotion, 29(2), 281-291. https://doi.org/10.1080/02699931.2014.913553

Csikszentmihalyi, M. (1975). Beyond boredom and anxiety. Jossey-Bass.

Csikszentmihalyi, M. (2000). The contribution of flow to positive psychology. In E. P. Seligman (Ed.), The science of optimism and hope: Research essays in honor of Martin (pp. 387-395). Templeton Foundation Press.

Csikszentmihalyi, M. (2014). Toward a psychology of optimal experience. In Flow and the foundations of positive psychology (pp. 209-226). Springer. https://doi.org/10.1007/978-94-017-9088-8_14

Csikszentmihalyi, M., \& Csikszentmihalyi, I. S. (1992). Optimal experience: Psychological studies of flow in consciousness. Cambridge University Press.

Csikszentmihalyi, M., \& Lefevre, J. (1989). Optimal experience in work and leisure. Journal of Personality and Social Psychology, 56, 815-822. https://doi.org/10.1037/0022-3514.56.5.815

Cuijpers, P. (2016). Meta-analysis in mental health: A practical guide.

Delrue, J., Mouratidis, A., Haerens, L., De Muynck, G.-J., Aelterman, N., \& Vansteenkiste, M. (2016). Intrapersonal achievement goals and underlying reasons among long distance runners: Their relation with race experience, self-talk, and running time. Psychologica Belgica, 56(3), 288-310. https://doi.org/10.5334/pb.280

Dietrich, A. (2003). Functional neuroanatomy of altered states of consciousness: The transient hypofrontality hypothesis. Consciousness and Cognition, 12(2), 231-256. https://doi.org/10.1016/ S1053-8100(02)00046-6

Downs, S. H., \& Black, N. (1998). The feasibility of creating a checklist for the assessment of the methodological quality both of randomised and non-randomised studies of health care interventions. Journal of Epidemiology \& Community Health, 52(6), 377-384. https://doi.org/10.1136/jech.52.6. 377

Durant, R. H. (1994). Checklist for the evaluation of research articles. Journal of Adolescent Health, 15 (1), 4-8. https://doi.org/10.1016/1054-139X(94)90381-6

Engeser, S., \& Rheinberg, F. (2008). Flow, performance and moderators of challenge-skill balance. Motivation and Emotion, 32(3), 158-172. https://doi.org/10.1007/s11031-008-9102-4

Eysenck, M. W., \& Wilson, M. R. (2016). Sporting performance, pressure and cognition: Introducing attentional control theory: Sport. In D. Groome \& M. Eysenck (Eds.), An introduction to applied cognitive psychology, 2nd ed (pp. 329-350). Routledge.

Fong, C. J., Zaleski, D. J., \& Leach, J. K. (2015). The challenge-skill balance and antecedents of flow: A meta-analytic investigation. The Journal of Positive Psychology, 10(5), 425-446. https://doi.org/10. 1080/17439760.2014.967799

Genaidy, A. M., LeMasters, G. K., Lockey, J., Succop, P., Deddens, J., Sobeih, T., \& Dunning, K. (2007). An epidemiological appraisal instrument - a tool for evaluation of epidemiological studies. Ergonomics, 50(6), 920-960. https://doi.org/10.1080/00140130701237667

Gurevitch, J., Koricheva, J., Nakagawa, S., \& Stewart, G. (2018). Meta-analysis and the science of research synthesis. Nature, 555(7695), 175-182. https://doi.org/10.1038/nature25753

Hagger, M. S., \& Chatzisarantis, N. L. D. (2007). Intrinsic motivation and self-determination in exercise and sport (pp. $X v$, 375). Human Kinetics.

Harrer, M., Cuijpers, P. D. P., Furukawa, P. D. T. A., \& Ebert, A. P. D. D. D. (2019). Doing meta-analysis in $R: A$ hands-on guide. https://bookdown.org/MathiasHarrer/Doing_Meta_Analysis_in_R/gosh-plot- 
analysis.html. https://bookdown.org/MathiasHarrer/Doing_Meta_Analysis_in_R/gosh-plotanalysis.html

Harris, D. J., Vine, S. J., \& Wilson, M. R. (2017a). Neurocognitive mechanisms of the flow state. Progress in Brain Research, 234, 221-243. https://doi.org/10.1016/bs.pbr.2017.06.012

Harris, D. J., Vine, S. J., \& Wilson, M. R. (2017b). Is flow really effortless? The complex role of effortful attention. Sport, Exercise, and Performance Psychology, 6(1), 103-114. https://doi.org/10.1037/ spy0000083

Harris, D. J., Vine, S. J., \& Wilson, M. R. (2017c). Flow and quiet eye: The role of attentional control in flow experience. Cognitive Processing, 18(3), 343-347. https://doi.org/10.1007/s10339-017-0794-9

Harris, D. J., Vine, S. J., \& Wilson, M. R. (2019). An external focus of attention promotes flow experience during simulated driving. European Journal of Sport Science, 19(6), 824-833. https://doi.org/ 10.1080/17461391.2018.1560508

Harris, D. J., Wilson, M. R., \& Vine, S. J. (2018). A systematic review of commercial cognitive training devices: Implications for use in sport. Frontiers in Psychology, 9. https://doi.org/10.3389/fpsyg. 2018.00709

Hempel, S., Suttorp, M. J., Miles, J. N., Wang, Z., Maglione, M., Morton, S., Johnsen, B., Valentine, D., \& Shekelle, P. G. (2011). Empirical evidence of associations between trial quality and effect size. Agency for Healthcare Research and Quality (US). https://www.ncbi.nlm.nih.gov/sites/books/ NBK56925/

Holt, J. (2016). Virtual domains for sports and games. Sport, Ethics and Philosophy, 10(1), 5-13. https://doi.org/10.1080/17511321.2016.1163729

Imai, K., Keele, L., Tingley, D., \& Yamamoto, T. (2011). Unpacking the black box of causality: Learning about causal mechanisms from experimental and observational studies. American Political Science Review, 105(4), 765-789. https://doi.org/10.1017/S0003055411000414

IntHout, J., loannidis, J. P., \& Borm, G. F. (2014). The Hartung-Knapp-Sidik-Jonkman method for random effects meta-analysis is straightforward and considerably outperforms the standard DerSimonian-Laird method. BMC Medical Research Methodology, 14(1), 25. https://doi.org/10. 1186/1471-2288-14-25

Jackman, P. C., Hawkins, R. M., Crust, L., \& Swann, C. (2019). Flow states in exercise: A systematic review. Psychology of Sport and Exercise, 45, 101546. https://doi.org/10.1016/j.psychsport.2019. 101546

Jackson, S. A. (1992). Athletes in flow: A qualitative investigation of flow states in elite figure skaters. Journal of Applied Sport Psychology, 4(2), 161-180. https://doi.org/10.1080/10413209208406459

Jackson, S. A., \& Csikszentmihalyi, M. (1999). Flow in sports. Human Kinetics.

Jackson, S. A., \& Eklund, R. C. (2002). Assessing flow in physical activity: The flow state scale-2 and dispositional flow scale-2. Journal of Sport and Exercise Psychology, 24(2), 133-150. https://doi.org/ 10.1123/jsep.24.2.133

Jackson, S. A., \& Kimiecik, J. C. (2008). The flow perspective of optimal experience in sport and physical activity. In T.S. Horn (Ed.), Advances in sport psychology, 3rd ed (pp. 377-399, 474-477). Human Kinetics.

Jackson, S. A., Thomas, P. R., Marsh, H. W., \& Smethurst, C. J. (2001). Relationships between flow, selfconcept, psychological skills, and performance. Journal of Applied Sport Psychology, 13(2), 129 153. https://doi.org/10.1080/104132001753149865

Jenny, S. E., Manning, R. D., Keiper, M. C., \& Olrich, T. W. (2017). Virtual(ly) athletes: Where eSports fit within the definition of "sport". Quest (grand Rapids, Mich ), 69(1), 1-18. https://doi.org/10.1080/ 00336297.2016.1144517

Jin, S.-A. A. (2012). "Toward integrative models of flow": effects of performance, skill, challenge, playfulness, and presence on flow in video games. Journal of Broadcasting \& Electronic Media, 56(2), 169-186. https://doi.org/10.1080/08838151.2012.678516

Kawabata, M., \& Mallett, C. J. (2011). Flow experience in physical activity: Examination of the internal structure of flow from a process-related perspective. Motivation and Emotion, 35(4), 393-402. https://doi.org/10.1007/s11031-011-9221-1 
Keller, J., \& Bless, H. (2008). Flow and regulatory compatibility: An experimental approach to the flow model of intrinsic motivation. Personality and Social Psychology Bulletin, 34(2), 196-209. https:// doi.org/10.1177/0146167207310026

Keller, J., \& Blomann, F. (2008). Locus of control and the flow experience: An experimental analysis. European Journal of Personality, 22(7), 589-607. https://doi.org/10.1002/per.692

Kiili, K., de Freitas, S., Arnab, S., \& Lainema, T. (2012). The design principles for flow experience in educational games. Procedia Computer Science, 15, 78-91. https://doi.org/10.1016/j.procs.2012. 10.060

Koehn, S., Donald, B., \& Paramei, G. (2018). Antecedents of flow and the flow-performance relationship in cricket. Kinesiology, 50(2), 277-284. https://doi.org/10.26582/k.50.2.6

Koehn, S., \& Morris, T. (2012). The relationship between performance and flow state in tennis competition. The Journal of Sports Medicine and Physical Fitness, 52(4), 437-447.

Koehn, S., Morris, T., \& Watt, A. P. (2013). Flow state in self-paced and externally-paced performance contexts: An examination of the flow model. Psychology of Sport and Exercise, 14(6), 787-795. https://doi.org/10.1016/j.psychsport.2013.06.001

Landhäußer, A., \& Keller, J. (2012). Flow and its affective, cognitive, and performance-related consequences. In S. Engeser (Ed.), Advances in flow research (pp. 65-85). Springer. https://doi.org/10. 1007/978-1-4614-2359-1_4

Mann, D. T. Y., Williams, A. M., Ward, P., \& Janelle, C. M. (2007). Perceptual-cognitive expertise in sport: A meta-analysis. Journal of Sport and Exercise Psychology, 29(4), 457-478. https://doi.org/ 10.1123/jsep.29.4.457

Marty-Dugas, J., \& Smilek, D. (2019). Deep, effortless concentration: Re-examining the flow concept and exploring relations with inattention, absorption, and personality. Psychological Research, 83 (8), 1760-1777. https://doi.org/10.1007/s00426-018-1031-6

Memmert, D. (2009). Pay attention! A review of visual attentional expertise in sport. International Review of Sport and Exercise Psychology, 2(2), 119-138. https://doi.org/10.1080/ 17509840802641372

Michailidis, L., Balaguer-Ballester, E., \& He, X. (2018). Flow and immersion in video games: The aftermath of a conceptual challenge. Frontiers in Psychology, 9. https://doi.org/10.3389/fpsyg.2018. 01682

Moher, D., Liberati, A., Tetzlaff, J., \& Altman, D. G. (2009). Preferred Reporting Items for Systematic Reviews and Meta-analyses: The PRISMA statement. PLOS Medicine, 6(7), e1000097. https://doi. org/10.1371/journal.pmed.1000097

Moran, A., \& Toner, J. (2017). A critical introduction to sport psychology: A critical introduction. Taylor \& Francis.

Nakamura, J., \& Csikszentmihalyi, M. (2002). The concept of flow. In S. J. Lopez, \& C. R. Snyder (Eds.), Handbook of positive psychology (pp. 89-105). Oxford University Press.

Nicholls, A. R., Polman, R. C. J., \& Holt, N. L. (2005). The effects of an individualized imagery interventions on flow states and golf performance. Athletic Insight, 7(1), http://eprints.bournemouth.ac. uk/22253/

Nieuwenhuys, A., \& Oudejans, R. R. D. (2012). Anxiety and perceptual-motor performance: Toward an integrated model of concepts, mechanisms, and processes. Psychological Research, 76(6), 747-759. https://doi.org/10.1007/s00426-011-0384-x

Norsworthy, C., Thelwell, R., \& Weston, N. (2017). Flow training, flow states, and performance in elite athletes. International Journal of Sport Psychology, 49), https://doi.org/10.7352/IJSP2018.49.134

Olkin, I., Dahabreh, I. J., \& Trikalinos, T. A. (2012). GOSH - a graphical display of study heterogeneity. Research Synthesis Methods, 3(3), 214-223. https://doi.org/10.1002/jrsm.1053

Payne, K. L., Wilson, M. R., \& Vine, S. J. (2019). A systematic review of the anxiety-attention relationship in far-aiming skills. International Review of Sport and Exercise Psychology, 12(0), 325-355. https://doi.org/10.1080/1750984X.2018.1499796

Pedraza-Ramirez, I., Musculus, L., Raab, M., \& Laborde, S. (2020). Setting the scientific stage for esports psychology: A systematic review. International Review of Sport and Exercise Psychology, 13(1), 319-352. https://doi.org/10.1080/1750984X.2020.1723122 
Peifer, C., Schulz, A., Schächinger, H., Baumann, N., \& Antoni, C. H. (2014). The relation of flow-experience and physiological arousal under stress - Can u shape it? Journal of Experimental Social Psychology, 53(Supplement C), 62-69. https://doi.org/10.1016/j.jesp.2014.01.009

Petticrew, M., \& Roberts, H. (2008). Systematic reviews in the social sciences: A practical guide. John Wiley \& Sons.

Podsakoff, P. M., MacKenzie, S. B., Lee, J.-Y., \& Podsakoff, N. P. (2003). Common method biases in behavioral research: A critical review of the literature and recommended remedies. Journal of Applied Psychology, 88(5), 879-903. https://doi.org/10.1037/0021-9010.88.5.879

Popay, J., Roberts, H., Sowden, A., Petticrew, M., Arai, L., Rodgers, M., Britten, N., Roen, K., \& Duffy, S. (2006). Guidance on the conduct of narrative synthesis in systematic reviews: A product from the ESRC methods programme. Lancaster University. https://doi.org/10.13140/2.1.1018.4643

Rheinberg, F. (2008). Intrinsic motivation and flow-experience. In H. Heckhausen \& J. Heckhausen (Eds.), Motivation and action (pp. 323-348). Cambridge University Press, Cambridge. 10.1017/ CBO9780511499821.014.

Rheinberg, F., Vollmeyer, R., \& Engeser, S. (2003). Die Erfassung des Flow-Erlebens. https://publishup. uni-potsdam.de/frontdoor/index/index/docld/551

Robazza, C. (2006). Emotion in Sport: An IZOF Perspective. 33.

Roberts, L. J., Jackson, M. S., \& Grundy, I. H. (2019). Choking under pressure: Illuminating the role of distraction and self-focus. International Review of Sport and Exercise Psychology, 12(1), 49-69. https://doi.org/10.1080/1750984X.2017.1374432

Schattke, K., Brandstätter, V., Taylor, G., \& Kehr, H. M. (2014). Flow on the rocks: Motive-incentive congruence enhances flow in rock climbing. International Journal of Sport Psychology, 45(6), 603-620. https://doi.org/10.7352/IJSP.2014.45.603

Schmidt, S. C. E., Gnam, J.-P., Kopf, M., Rathgeber, T., \& Woll, A. (2020). The influence of cortisol, flow, and anxiety on performance in E-sports: A field study [research article]. BioMed Research International. https://doi.org/10.1155/2020/9651245

Schüler, J., \& Brunner, S. (2009). The rewarding effect of flow experience on performance in a marathon race. Psychology of Sport and Exercise, 10(1), 168-174. https://doi.org/10.1016/j.psychsport. 2008.07.001

Sklett, V. H., Lorås, H. W., \& Sigmundsson, H. (2018). Self-Efficacy, flow, affect, worry and performance in elite world Cup Ski jumping. Frontiers in Psychology, 9, 1215. https://doi.org/10.3389/fpsyg. 2018.01215

Stavrou, N. A., Jackson, S. A., Zervas, Y., \& Karteroliotis, K. (2007). Flow experience and Athletes' performance with Reference to the orthogonal model of flow. The Sport Psychologist, 21(4), 438-457. https://doi.org/10.1123/tsp.21.4.438

Stavrou, N. A., \& Zervas, Y. (2004). Confirmatory factor analysis of the Flow State Scale in sports. International Journal of Sport and Exercise Psychology, 2(2), 161-181. https://doi.org/10.1080/ 1612197X.2004.9671739

Swann, C., Crust, L., Jackman, P., Vella, S. A., Allen, M. S., \& Keegan, R. (2017). Psychological states underlying excellent performance in sport: Toward an integrated model of flow and clutch states. Journal of Applied Sport Psychology, 29(4), 375-401. https://doi.org/10.1080/10413200. 2016.1272650

Swann, C., Keegan, R., Crust, L., \& Piggott, D. (2016). Psychological states underlying excellent performance in professional golfers: "letting it happen" vs. "making it happen". Psychology of Sport and Exercise, 23, 101-113. https://doi.org/10.1016/j.psychsport.2015.10.008

Swann, C., Keegan, R. J., Piggott, D., \& Crust, L. (2012). A systematic review of the experience, occurrence, and controllability of flow states in elite sport. Psychology of Sport and Exercise, 13(6), 807819. https://doi.org/10.1016/j.psychsport.2012.05.006

Swann, C., Piggott, D., Schweickle, M., \& Vella, S. A. (2018). A review of scientific progress in flow in sport and exercise: Normal science, crisis, and a progressive shift. Journal of Applied Sport Psychology, 30(3), 249-271. https://doi.org/10.1080/10413200.2018.1443525

van Hilvoorde, I., \& Pot, N. (2016). Embodiment and fundamental motor skills in eSports. Sport, Ethics and Philosophy, 10(1), 14-27. https://doi.org/10.1080/17511321.2016.1159246 
Viechtbauer, W. (2010). Conducting meta-analyses in R with the metafor package. Journal of Statistical Software, 36(3), 1-48. https://doi.org/10.18637/jss.v036.i03

Wulf, G. (2013). Attentional focus and motor learning: A review of 15 years. International Review of Sport and Exercise Psychology, 6(1), 77-104. https://doi.org/10.1080/1750984X.2012.723728

Yarrow, K., Brown, P., \& Krakauer, J. W. (2009). Inside the brain of an elite athlete: The neural processes that support high achievement in sports. Nature Reviews Neuroscience, 10(8), 585-596. https://doi.org/10.1038/nrn2672

Yoshida, K., Sawamura, D., Inagaki, Y., Ogawa, K., Ikoma, K., \& Sakai, S. (2014). Brain activity during the flow experience: A functional near-infrared spectroscopy study. Neuroscience Letters, 573, 30-34. doi:10.1016/j.neulet.2014.05.011 